\title{
From runoff to rainfall: inverse rainfall-runoff modelling in a high temporal resolution
}

\author{
M. Herrnegger, H. P. Nachtnebel, and K. Schulz \\ Institute of Water Management, Hydrology and Hydraulic Engineering, University of Natural Resources \\ and Life Sciences, Vienna, Austria \\ Correspondence to: M. Herrnegger (mathew.herrnegger@boku.ac.at)
}

Received: 16 November 2014 - Published in Hydrol. Earth Syst. Sci. Discuss.: 5 December 2014

Revised: 5 November 2015 - Accepted: 6 November 2015 - Published: 23 November 2015

\begin{abstract}
Rainfall exhibits a large spatio-temporal variability, especially in complex alpine terrain. Additionally, the density of the monitoring network in mountainous regions is low and measurements are subjected to major errors, which lead to significant uncertainties in areal rainfall estimates. In contrast, the most reliable hydrological information available refers to runoff, which in the presented work is used as input for an inverted HBV-type rainfall-runoff model that is embedded in a root finding algorithm. For every time step a rainfall value is determined, which results in a simulated runoff value closely matching the observed runoff. The inverse model is applied and tested to the Schliefau and Krems catchments, situated in the northern Austrian Alpine foothills. The correlations between inferred rainfall and station observations in the proximity of the catchments are of similar magnitude compared to the correlations between station observations and independent INCA (Integrated Nowcasting through Comprehensive Analysis) rainfall analyses provided by the Austrian Central Institute for Meteorology and Geodynamics (ZAMG). The cumulative precipitation sums also show similar dynamics. The application of the inverse model is a promising approach to obtain additional information on mean areal rainfall. This additional information is not solely limited to the simulated hourly data but also includes the aggregated daily rainfall rates, which show a significantly higher correlation to the observed values. Potential applications of the inverse model include gaining additional information on catchment rainfall for interpolation purposes, flood forecasting or the estimation of snowmelt contribution. The application is limited to (smaller) catchments, which can be represented with a lumped model setup, and to the estimation of liquid rainfall.
\end{abstract}

\section{Introduction}

The motivation for the concept presented in this paper comes from practical hydrological problems. Some years back we set up rainfall-runoff models for different alpine rivers (e.g. Stanzel et al., 2008; Nachtnebel et al., 2009a, b, 2010a, b). In the course of these projects, we were confronted with massive errors in the precipitation input fields. This is a known problem, especially in alpine environments. Although the temporal dynamics in the runoff simulations were captured quite well, significant mass balance errors between observed and simulated runoff were found. It could be excluded that erroneous evapotranspiration calculations were biasing the results (Herrnegger et al., 2012). In the HYDROCAST project (Bica et al., 2011) we tested different precipitation interpolation and parameterisation schemes by using the ensemble of generated inputs for driving a rainfall-runoff model and comparing the simulated runoff time series with observations. In essence, the results showed that no significant improvements could be made in the runoff simulations and that the information on the precipitation fields is strongly determined and limited by the available station time series. Runoff observations as an additional information source constitute a good proxy to precipitation observations with a considerably lower level of associated uncertainty. The main aim is therefore to present a proof of concept for the inversion of a conceptual rainfall-runoff model; that is, to show that it is possible to use a widely applied model concept to calculate mean areal rainfall from runoff observations. 
Table 1. Magnitude of different systematic errors in precipitation measurements (Sevruk, 1981, 1986; Goodison et al, 1998; Elias et al., 1993; Jacobs et al., 2006; Klemm and Wrzesinsky, 2007).

\begin{tabular}{ll}
\hline Systematic error & Magnitude \\
\hline Wind-induced errors & $2-10 \%$ (liquid precipitation) \\
& $10->50 \%$ (snow) \\
Wetting losses & $2-10 \%$ \\
Evaporation losses & $0-4 \%$ \\
Splash-out and splash-in & $1-2 \%$ \\
Fog and dew & $4-10 \%$ \\
\hline
\end{tabular}

\subsection{Uncertainties in catchment precipitation}

Areal or catchment precipitation estimates are fundamental, as they represent an essential input for modelling hydrological systems. They are however subject to manifold uncertainties, since it is not possible to observe the mean catchment rainfall itself (Sugawara, 1992; Valéry et al., 2009). Catchment rainfall values are therefore generally estimated by interpolation of point measurements, sometimes incorporating information on the spatial rainfall structure from remote sensing, e.g. radar (e.g. Haiden et al., 2011). Measurement, sample and model errors can be identified as sources of uncertainty. Point observations of rainfall, which are the basis for the calculation of mean areal rainfall values, are error inflicted (Sevruk, 1981, 1986; Goodison et al., 1998; Sevruk and Nespor, 1998; Seibert and Moren, 1999; Wood et al., 2000; Fekete et al., 2004). Occult precipitation forms like fog or dew are frequently ignored. Although not generally relevant, this precipitation form can be a significant contribution to the water budget of a catchment (Elias et al., 1993; Jacobs et al., 2006; Klemm and Wrzesinsky, 2007). The highest systematic measurement errors of over $50 \%$ are found during snowfall in strong wind conditions. Other sources of systematic measurement errors and their magnitudes are listed in Table 1 .

In complex terrain the rainfall process is characterised by a high temporal and spatial variability. Especially in these areas, the density of the measurement network tends to be low, not capturing the high variability and leading to sample errors (Wood et al., 2000; Simoni et al., 2011; de Jong et al., 2002). Further uncertainties arise in the interpolation of catchment-scale rainfall from point observations. Systematic and stochastic model errors of the regionalisation methods can be identified. Systematic model errors can arise during the regionalisation of rainfall in alpine areas, when e.g. the elevation dependency is not considered (Haiden and Pistotnik, 2009). Quantitative areal rainfall estimates from radar products are, although they contain precious information on the rainfall structure, still afflicted with significant uncertainties (Krajewski et al., 2010; Krajewski and Smith, 2002). A general magnitude of overall uncertainty, which arises during the generation of areal rainfall fields, is difficult to assess, as different factors, e.g. topography, network density and regionalisation method, play a role.

\subsection{Uncertainties in runoff observations}

Errors in runoff measurements are far from negligible (Di Baldassarre and Montanari, 2009; McMillan et al., 2010; Pappenberger et al., 2006; Pelletier, 1987). When applying the rating-curve method for estimation of river discharge the uncertainties are a function of the quality of the rating curve and the water level measurements. The quality of the rating curve depends on (i) the quality and stability of the measured cross section over time, (ii) the representativeness of the velocity measurements and (iii) the influence of steady and unsteady flow conditions. According to literature the overall uncertainty can vary in the range of 5-20\% (Di Baldassarre and Montanari, 2009; Pelletier, 1987). Although it can be expected that the measurement error will certainly be large during flood events due to its dynamic features, the errors are considerably lower compared to rainfall measurements and to the uncertainties introduced when calculating mean areal rainfall. It must be assumed, however, that transboundary flows and groundwater flows around the gauging station are negligible.

\subsection{Catchment precipitation from runoff observations through inverse modelling}

A classical application of hydrology, the problem of reproducing observed runoff with meteorological forcings as input through a formalised representation of reality, is a forward or direct problem. Two inverse problems related to this forward problem can be identified (Groetsch, 1993).

1. Causation problem: determination of input $I$ (cause), with given output $O$ (effect) and given model $K$, including model parameters $\theta$ (process).

2. Model identification problem: determination of model $K$, given input $I$ and output $O$.

The model identification problem can be divided into (i) the problem of identifying the model structure itself and (ii) the determination of model parameters that characterise the system (Tarantola, 2005). The focus in this contribution lies in solving the causation problem, i.e. in the determination of rainfall input from runoff, with a given model structure and parameters. In the following, the model, which calculates mean catchment rainfall values from runoff, will be called the inverse model. The conventional model, which uses rainfall and potential evapotranspiration as input to calculate runoff, will be called the forward model.

Runoff from a closed catchment is the integral of rainfall minus evapotranspiration losses and change in water storage over a certain period of time. Therefore, runoff observations can be used to derive information on rainfall. This has been done in several studies (e.g. Bica et al., 2011; Valéry et 
al., 2009, 2010; Ahrens et al., 2003; Jasper and Kaufmann, 2003; Kunstmann and Stadler, 2005; Jasper et al., 2002). The common basis of these studies was to indirectly gain information on catchment rainfall by comparing simulated runoff results with observations. Hino and Hasabe (1981) fitted an AR (autoregressive) model to daily runoff data, while assuming rainfall to be white noise. By inverting the AR model they directly generated time series of rainfall from runoff. Vrugt et al. (2008) and Kuczera et al. (2006) derived rainfall multipliers or correction factors from streamflow with the DREAM (DiffeRential Evolution Adaptive Metropolis) and BATEA (BAyesian Total Error Analysis) methods; however, these methods are computationally intensive. In a well-received study, Kirchner (2009) analytically inverted a single-equation rainfall-runoff model to directly infer time series of catchment rainfall values from runoff. The Kirchner model (when deriving the storage-discharge relationship directly from runoff data) only has a single parameter and does not explicitly need rainfall as driving input for calibration. Rainfall data are however needed for the determination of rainless periods for the estimation of the sensitivity function. Krier et al. (2012) applied the model of Kirchner (2009) to 24 small and mesoscale catchments in Luxembourg to generate areal rainfall. No systematic differences in the quality of the rainfall estimates are found between different catchment sizes. In periods with higher soil moisture, however, the rainfall simulations show a higher performance. The parsimonious approach of Kirchner (2009) is limited to catchments where discharge is determined by the volume of water in a single storage and which can be characterized as simple firstorder nonlinear dynamical systems. Also due to the larger number of model parameters describing several linked storages, accounting for a variety of different runoff components, HBV-type conceptual models offer higher degrees of freedom and flexibility in the calibration procedure. They can, in consequence, be applied to catchments with a wider range of runoff characteristics (Bergström, 1995; Kling et al., 2015; Kling, 2006; Perrin et al., 2001). Therefore, in this study, the conceptual rainfall-runoff model COSERO (COntinuous SEmi-distributed RunOff Model; Nachtnebel et al., 1993; Eder et al., 2005; Kling and Nachtnebel, 2009; Herrnegger et al., 2012; Kling et al., 2015; among others), which in its structure is similar to the HBV model, is used as a basis for the inverse model. The COSERO model has been frequently applied in research studies and in engineering projects (see Kling et al., 2015 for details).

This paper is organised as follows: following this introduction the Methods section describes the conventional conceptual rainfall-runoff model (forward model) and the inverse model, including the preconditions and limitations of its application. The concept of virtual experiments to test the invertibility of the inverse model and to analyse the effects of errors in the discharge measurements on the inverse rainfall simulations are presented. Additionally, the setup of different simulation experiments, e.g. to evaluate the influence

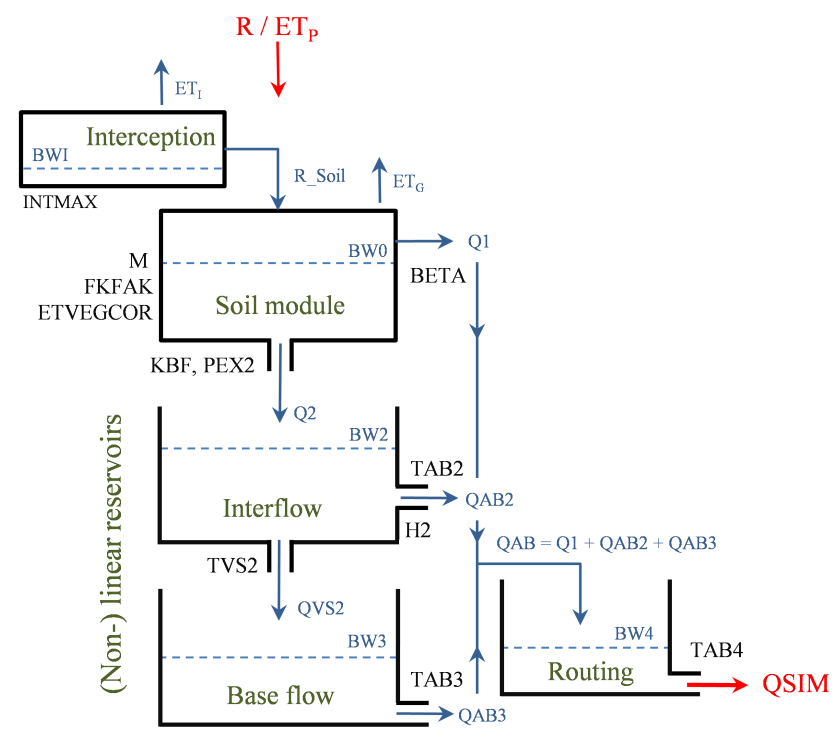

Figure 1. Structure, parameters and states of the forward model.

of differing calibration periods or possible runoff measurement errors on the simulations, are explained. The inverse model is applied to two headwater catchments in the foothills of the northern Austrian Alps, with differing hydro-climatic and physical conditions. The catchments and the database, including the calibration periods for the simulation experiments, are presented. The runoff simulations of the forward model and the rainfall simulations of the inverse model are described in detail in the results and discussion section. Finally, the paper ends with a summary and outlook.

\section{Methods}

\subsection{Forward model (rainfall-runoff model)}

In the state-space-formulated forward model, the unknown runoff $Q_{t}$ is a function $f$ of the known variables rainfall input $R_{t}$, potential evapotranspiration $\mathrm{ET}_{\mathrm{p}_{t}}$, system states $S_{t-1}$ and a set of model parameters $\theta_{i}$, whereas the index $t$ denotes time:

$Q_{t}=f\left(R_{t}, \mathrm{ET}_{\mathrm{p}_{t}}, S_{t-1} \mid \theta_{i}\right)$.

The rainfall-runoff model is based on the COSERO model (see introduction for references) but has a simpler model structure. It includes an interception and soil module and three reservoirs for interflow, baseflow and routing. The model structure is shown in Fig. 1, model parameters are summarised in Table 2 and fluxes and system states in Table 3 .

The COSERO model is formulated in a state space approach, with state transition functions,

$S_{t}=f\left(S_{t-1}, I_{t} \mid \theta_{i}\right)$, 
Table 2. Model parameters $\theta_{i}$. Parameters in italics are calibrated.

\begin{tabular}{llll}
\hline Parameter & Units & Range & Description \\
\hline INTMAX & $\mathrm{mm}$ & $0.5-2.5$ & Interception storage capacity \\
$M$ & $\mathrm{~mm}$ & $80-250$ & Soil storage capacity \\
FKFAK & - & $0.5-1$ & Critical soil moisture for actual evapotranspiration \\
ETVEGCOR & - & $0.4-1.1$ & Vegetation correction factor for actual evapotranspiration from soil \\
$B E T A$ & - & $0.1-10$ & Exponent for computing fast runoff generation \\
KBF & $\mathrm{h}$ & $4000-12000$ & Recession coefficient for percolation from soil module \\
$P E X 2$ & - & $5-25$ & Parameter for nonlinear percolation \\
$T A B 2$ & $\mathrm{~h}$ & $50-500$ & Recession coefficient for interflow \\
$T V S 2$ & $\mathrm{~h}$ & $50-500$ & Recession coefficient for percolation from interflow reservoir \\
$H 2$ & $\mathrm{~mm}$ & $0-25$ & Outlet height for interflow \\
$T A B 3$ & $\mathrm{~h}$ & $1000-5000$ & Recession coefficient for baseflow \\
$T A B 4$ & $\mathrm{~h}$ & $0.05-10$ & Recession coefficient for routing \\
\hline
\end{tabular}

Table 3. Model fluxes and system states $S_{i}$. Fluxes represent sums over the time step.

\begin{tabular}{|c|c|c|c|}
\hline Variable & Units & Type & Description \\
\hline$R$ & $\mathrm{~mm}$ & Input & Rainfall \\
\hline $\mathrm{ET}_{\mathrm{p}}$ & $\mathrm{mm}$ & Input & Potential evapotranspiration \\
\hline $\mathrm{ET}_{\mathrm{I}}$ & $\mathrm{mm}$ & Output & $\begin{array}{l}\text { Actual evapotranspiration } \\
\text { from interception module }\end{array}$ \\
\hline $\mathrm{ET}_{\mathrm{G}}$ & $\mathrm{mm}$ & Output & $\begin{array}{l}\text { Actual evapotranspiration } \\
\text { from soil module }\end{array}$ \\
\hline$B_{\mathrm{WI}}$ & $\mathrm{mm}$ & State & $\begin{array}{l}\text { Water stored in } \\
\text { interception module }\end{array}$ \\
\hline $\mathrm{B}_{\mathrm{W}_{0}}$ & $\mathrm{~mm}$ & State & Water stored in soil module \\
\hline $\mathrm{B}_{\mathrm{W}_{2}}$ & $\mathrm{~mm}$ & State & $\begin{array}{l}\text { Water stored } \\
\text { in interflow reservoir }\end{array}$ \\
\hline $\mathrm{B}_{\mathrm{W}_{3}}$ & $\mathrm{~mm}$ & State & $\begin{array}{l}\text { Water stored } \\
\text { in baseflow reservoir }\end{array}$ \\
\hline $\mathrm{B}_{\mathrm{W}_{4}}$ & $\mathrm{~mm}$ & State & $\begin{array}{l}\text { Water stored } \\
\text { in routing reservoir }\end{array}$ \\
\hline R_Soil & $\mathrm{mm}$ & Internal flux & Input into soil module \\
\hline$Q_{1}$ & $\mathrm{~mm}$ & Internal flux & Fast runoff from soil module \\
\hline$Q_{2}$ & $\mathrm{~mm}$ & Internal flux & Percolation from soil module \\
\hline$Q_{\mathrm{AB} 2}$ & $\mathrm{~mm}$ & Internal flux & Interflow \\
\hline$Q_{\mathrm{VS} 2}$ & $\mathrm{~mm}$ & Internal flux & $\begin{array}{l}\text { Percolation from } \\
\text { interflow reservoir }\end{array}$ \\
\hline$Q_{\mathrm{AB} 3}$ & $\mathrm{~mm}$ & Internal flux & Baseflow \\
\hline$Q_{\text {sim }}$ & $\mathrm{mm}$ & Output & Total runoff \\
\hline
\end{tabular}

and output functions,

$O_{t}=g\left(S_{t-1}, I_{t} \mid \theta_{i}\right)$

where

- $I_{t}$ represents input, e.g. rainfall,

- $O_{t}$ represents output, e.g. total runoff,

- $S_{t}$ represents system states, e.g. water stored in soil module,
- $\theta_{i}$ represents model parameters.

So, the model state and the output at time $t$ depend only and exclusively on the previous state $S_{t-1}$, the inputs $I_{t}$ and parameters $\theta_{i}$. The simplified model formulation can be found in the Appendix.

\subsection{Inverse model (runoff-rainfall model)}

In the inverse model the unknown rainfall $R_{t}$ is a function of runoff $Q_{t}$, potential evapotranspiration $\mathrm{ET}_{\mathrm{p}_{t}}$, system states $S_{t-1}$ and a given set of model parameters $\theta_{i}$, where again the index $t$ denotes time:

$R_{t}=f^{-1}\left(Q_{t}, \mathrm{ET}_{\mathrm{p}_{t}}, S_{t-1} \mid \theta_{i}\right)$

If Eq. (4) is invertible and given $\mathrm{ET}_{\mathrm{p}_{t}}, S_{t-1}$ and $\theta_{i}$, there is only one single input $I_{t}$, which results in an output $O_{t}$ (Eq. 3). To calculate the inverse rainfall rate the forward model is embedded in a search algorithm to find, for every time step $t$, the rainfall rate $R_{t}$ that best fits the observed runoff:

$f\left(R_{t}\right)=Q_{\mathrm{sim}_{t}}\left(R_{t}, \mathrm{ET}_{\mathrm{p}_{t}}, S_{t-1} \mid \theta_{i}\right)-Q_{\mathrm{obs}_{t}} \leq \varepsilon$,

with

$R_{t, \min } \leq R_{t}<R_{t, \max }$

The upper and lower brackets of rainfall $\left(R_{t, \min }\right.$ and $R_{t, \max }$ ) are set to 0 and $50 \mathrm{~mm} \mathrm{~h}^{-1}$. The value of the upper bound is an arbitrary value, but any reasonable bounds can be applied. $Q_{\text {sim }_{t}}$ and $Q_{\mathrm{obs}_{t}}$ are the simulated and observed runoff, respectively. $\varepsilon$ denotes a small value, which is ideally zero.

Solving Eq. (5), which reflects the objective function used in the search algorithm, is basically a root finding problem. Different root finding algorithms were tested, with the Van Wijngaarden-Dekker-Brent method (Brent, 1973; Press et al., 1992) being the method of choice, as it exhibited the 


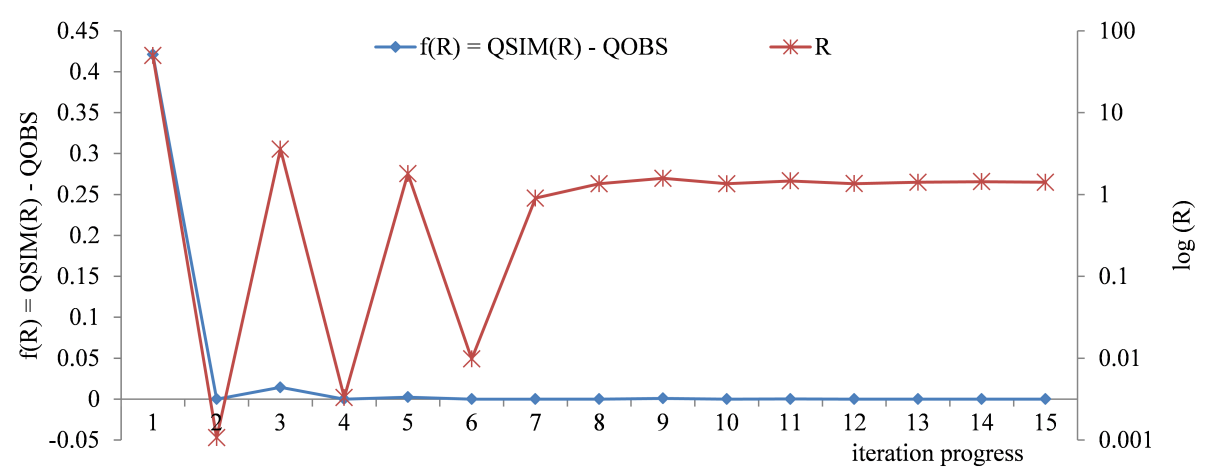

Figure 2. Illustration of the iteration progress for one model time step. Note that the right $y$ axis showing the inverse rainfall values $(R)$ is in a logarithmic scale (units in $\mathrm{mm} \mathrm{h}^{-1}$ ).

fastest results. The Brent method combines root bracketing, bisection and inverse quadratic interpolation to converge from the neighbourhood of a zero crossing and will always converge, as long as the function can be evaluated within the initial defined interval (in our case $R_{t, \min }$ and $R_{t, \max }$ ) known to contain a root (Press et al., 1992). The iteration progress for one model time step is illustrated in Fig. 2. The left $y$ axis shows the objective function values and the right $y$ axis (in logarithmic scale) the associated rainfall values estimated during the iteration procedure.

The state space approach of the model is a first-order Markov process: the system states $S_{t}$ and outputs $O_{t}$ of the calculation time step depend only on the preceding states $S_{t-1}$ and some inputs $I_{t}$ and not on the sequences of system states that preceded it, e.g. $S_{t-2}, S_{t-3}, \ldots, S_{t-n}$ (see Eqs. 2 and 3). All information of the sequence of the preceding inputs $\left(I_{t-1}, I_{t-2}, \ldots, I_{t-n}\right)$ is implicitly included in the last relevant system state $S_{t-1}$. No hysteretic effects are considered in the model and it does not include a parameter which introduces a lag effect between inputs and outputs.

Given the model structure, parameters and potential evapotranspiration as input, the inverse rainfall and resulting runoff are solely a function of the initial cold system states. The influence of the initial cold system states on the inverse rainfall calculation is analysed in the results section.

The determined rainfall value $R_{t}$ represents the "best"simulated rainfall of the catchment and is also used as input into the forward model to simulate runoff. Therefore, for every time step, the inverse model simulates a rainfall and corresponding runoff value and also resulting system states. The simulated runoff value should ideally be identical to the observed value. This is however not always the case, as will be shown later.

A more elegant method to calculate rainfall from runoff is by analytically inverting the equations of a given model, i.e. bringing the rainfall term onto the right side of the equation. In Herrnegger (2013) this method was presented but showed some disadvantages. The model structure, which was used in Herrnegger (2013) and which can be inverted ana- lytically, differs from the model presented here. It does not include interception and routing. Additionally, the inversion is not possible in certain periods, since the discontinuities introduced by threshold values lead to noninvertibility in the analytical solution. The precondition that the rainfall-runoff model is invertible is violated in certain periods. For the forward model used here, an internal time step discretization is included in the model code to guarantee that the transition between system states above and below the threshold value within a time step are solved exactly. This is not possible in the analytical solution presented in Herrnegger (2013), since no internal time step discretization can be implemented.

\section{Preconditions and limitations of the application of the inverse model}

It is assumed that runoff from the catchment passes through the measurement cross section of the gauging station and that subsurface and transboundary flows are negligible. It is difficult to apply the inverse model to leaky catchments or catchments where a significant part of the runoff is not observed at the gauging site. Even with a given quantification of the leakage process, the application of the inverse model would lead to an additional uncertainty difficult to quantify. Since a novel approach is presented, it is also reasonable to exclude this possible source of error at this point. This is however not necessarily a limitation of the inverse model. Also, the application of a forward hydrological model, which needs to be calibrated against runoff observations, will fail or will result in wrong estimates of water balance components.

The inverse model is based on a lumped model setup and the resulting inverse rainfall value corresponds to the mean areal rainfall. Applying a spatially distributed model is not possible, since the origin of outputs of different zones or cells of a distributed model setup cannot be reproduced by the inverse model in a deterministic way without additional assumptions. The information of origin gets lost as soon as cell values are summed and routed to a catchment runoff value. It is however conceivable to spatially disaggregate the mean 
areal rainfall from the inverse model using additional information, e.g. assuming an elevation dependency on rainfall.

Solid precipitation is accumulated without any direct signal on the hydrograph. It is therefore impossible to use the inverse model to estimate solid precipitation. The inverse model can only be used to calculate rainfall in snow-free catchments or, as in our case, periods in which runoff is not influenced by snowmelt (i.e. summer months). However, in rainless periods, where it is clear that snowmelt is dominating runoff (e.g. in spring), the inverse model can be used to quantify snowmelt rates from a catchment.

The applicability of the inverse model is limited to catchments which are representable with a lumped model setup and the proposed model structure. If a catchment is too large, it will be generally difficult to simulate that system with a lumped model setup - not necessarily because of neglecting spatial heterogeneity in the model parameters (although this may also be an issue) or ignoring a lag between the rainfall and runoff signal, but simply because the lumped rainfall input used is "wrong" and is not representable for the whole catchment. If it only rains in the headwaters of a large catchment, the lumped input into the forward model for this time step or rainfall event will be much lower, since it will be spatially aggregated. This input is not applicable to the whole catchment and the simulations will show deficits. In this case, an inversion will be highly flawed. This consideration is independent of the fact that the sampling of rainfall fields in larger catchments tends to be statistically better compared to smaller catchments, where observations are rarer.

It is also clear that catchments, independent of size, exist where the application of this particular model structure will fail (e.g. flatland catchments dominated by groundwater). If hydro-meteorological conditions of the catchment change or are different from the calibration period and the forward model (e.g. due to poor parameter estimation, inadequate model structure and wrong representation of the real world prototype) is not able to capture these changes, then again the calculation of rainfall from runoff will fail (as they do for the forward case). However, if the forward model can be fitted to the observed runoff data and as long as the forward model is able to represent the catchment responses to rainfall, an inversion will be possible.

\subsection{Simulation setups}

\subsubsection{Virtual experiments}

In a first step the inverse model is evaluated and tested with virtual experiments, in order to guarantee that the model equations are invertible. Runoff simulations are performed with the forward model driven by observed rainfall as input. The simulated runoff time series of the forward models are then used as input into the inverse model, with the aim to reproduce the observed rainfall. Simulated runoff from the forward model is dependent on the model parameters. There-

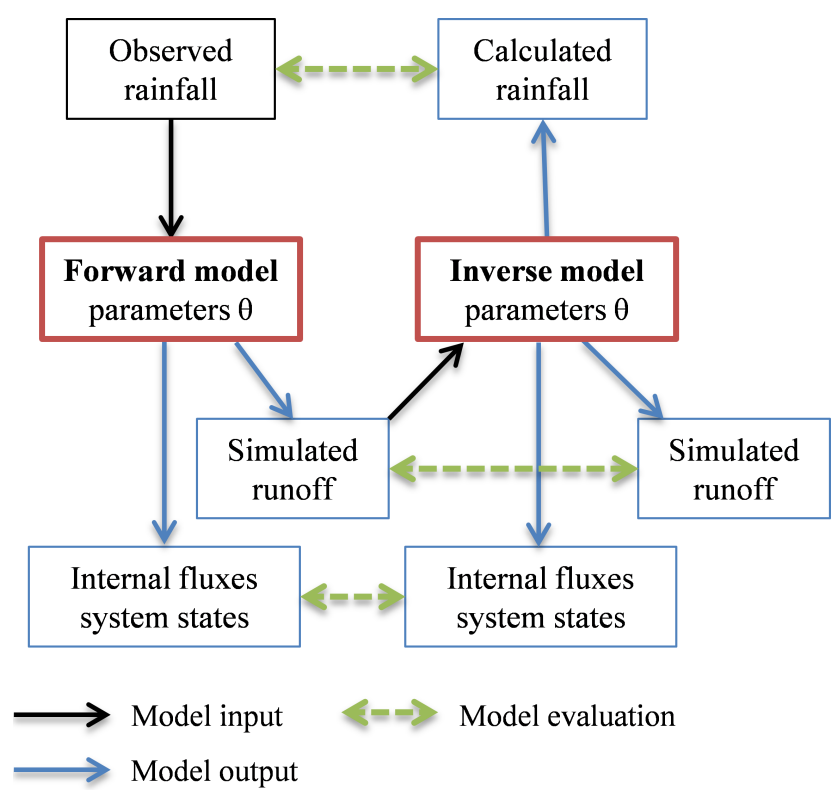

Figure 3. Setup of the virtual experiments and evaluation of the inverse model. All variables are calculated for every Monte Carlo run in which parameters $\theta$ are varied.

fore, to test the inversion procedure for the whole parameter range, synthetic hydrographs are produced with Monte Carlo simulations. A total of 20000 different parameter combinations are chosen randomly from the parameter space, with the same number of model runs to evaluate the inverse model. The sampled parameters and associated range are shown in Table 2. The schematic setup of the virtual experiment and the evaluation of the inverse model is shown in Fig. 3. Note that the setup and the evaluation is performed for every individual Monte Carlo run, as the simulated runoff from the forward model varies depending on selected model parameters.

All system states and fluxes of the forward model are perfectly known at every time step. This information is used to evaluate the inverse model by calculating the bias between forward and inverse simulation result of system states and fluxes. Only after a successful evaluation of the inverse model with the virtual experiments can observations of runoff be used as input into the inverse models.

Additionally, virtual experiments are performed, in which random noise drawn from a zero-mean normal distribution and rescaled to represent a range of measurement errors is added to a runoff simulation of the forward model. These time series are then used as input into the inverse model to test the sensitivity of the inferred precipitation rates to shortterm errors in the discharge measurements:

$Q_{-} F N_{i, t}=Q_{-} F_{t}+Q_{-} F_{t} N\left(\mu, \sigma^{2}\right) \alpha_{i}$,

with

- $Q \_F N_{i, t}$ as noisy input into inverse model, 
- $Q_{-} F_{t}$ as forward simulated runoff based on observed precipitation,

- $N\left(\mu, \sigma^{2}\right)$ as normal distribution with mean $\mu=0$ and standard deviation $\sigma^{2}=1$,

- $\alpha_{i}$ as noise scaling factor: $0,1,2,5$ and $10 \%$.

\subsubsection{Model calibration and simulations experiments with observed data}

The application of the inverse model is based on the assumption that the forward model can represent the catchment responses to rainfall. The forward model is therefore calibrated against runoff observations, using observed rainfall values. The calibration setup and in consequence model parameters (for a given model structure) can depend on (i) the calibration period and length and (ii) the driving input used. The inverse rainfall is also a function of the observed runoff, which may also exhibit possible measurement errors. Finally, the initial conditions of the system states at the beginning of the simulations also influence not only the results of the forward model but also those of the inverse model. To evaluate these influences, i.e. different model parameters due to different calibration periods and lengths, different runoff observations, different parameter optimisation databases and different initial conditions, several simulation experiments are performed. An overview table of the simulation experiments can be found in Sect. 3.3 after the presentation of the available data. In addition to the calibration period, all simulation experiments include independent validation periods, which allow testing the inverse model in periods in which no observed rainfall was used.

In a first step three different periods are used for calibration of the model parameters. In a further simulation experiment, the runoff observation is increased by a constant offset of $10 \%$ to evaluate the influence of possible systematic streamflow errors on the simulations and the inverse rainfall. A fifth experiment is performed, in which an independent rainfall realisation is used as driving input for model calibration, in order to test the conditioning of the model parameters and in consequence the simulations to the driving input. Given the model structure, the inverse rainfall is a function of observed runoff, potential evapotranspiration, system states and model parameters (Eq. 4). Extending Eq. (4) explicitly with all relevant system states leads to

$$
\begin{aligned}
R_{t}= & f^{-1}\left(Q_{t}, \mathrm{ET}_{\mathrm{p}_{t}}, B_{\mathrm{WI}_{t-1}}, B_{\mathrm{W}_{t-1}},\right. \\
& \left.B_{\mathrm{W} 2_{t-1}}, B_{\mathrm{W} 3_{t-1}}, B_{\mathrm{W}_{t-1}} \mid \theta_{i}\right) .
\end{aligned}
$$

The forward and inverse models are run as a continuous simulation in time. The preceding system states are therefore an integral part of the simulation and are determined intrinsically within the simulation. However, the initial system states at the beginning of the simulation period (cold states) will influence the results of the simulation and should, after an adequate spin-up time, not influence the runoff but also inverse rainfall simulations. Therefore, a sixth experiment was set up, in which three strongly differing cold start scenarios are defined:

- reference scenario,

- dry system states scenario,

- wet system states scenario.

For the reference scenario the system states from the continuous simulation were used. For the cold states, in the dry scenario the states from the reference scenario were reduced by a factor of 0.5 and increased by a factor of 1.5 for the wet scenario.

The simulation experiments do not allow for a systematic analysis of parameter uncertainty, since this is not the aim of this paper. The simulation experiments however enable a first assessment of the robustness of the results and to evaluate the forward and inverse model performance, when the conditions are different from the conditions the model has been calibrated against (i.e. validation period) or if different driving inputs are used.

The model structure applied includes 12 parameters, of which 10 have to be calibrated. Two parameters (INTMAX and ETVEGCOR) are estimated a priori (see Table 2). The interception storage is represented by the model parameter INTMAX, which is estimated as a function of the land use and month of year to consider changes of interception within the annual cycle. ETVEGCOR, comparable to the widely used crop coefficient (Allen et al., 1998), is also estimated depending on the month of year and land use. Values for INTMAX and ETVEGCOR can be found in Herrnegger et al. (2012). For the application, monthly INTMAX and ETVEGCOR values were calculated as area-weighted mean values, depending on the land uses in the catchments, since a lumped setup is used. For the implementation of the evapotranspiration calculations in the model the reader is also referred to Kling et al. (2015).

Generally only June, July, August and September are used, since it can be guaranteed that no snowmelt influences runoff in these months (see Sect. 2.2.1). Parameter calibration in the simulation experiments is performed for the forward model, using the shuffled complex evolution algorithm (Duan et al., 1992). As an optimisation criterion the widely used NashSutcliffe efficiency (NSE; Nash and Sutcliffe, 1970) was chosen.

\section{Materials}

\subsection{Study areas}

The inverse model is applied to two catchments with different size, geology and land use located at the foothills of the northern Alps. The Schliefau catchment is located about 


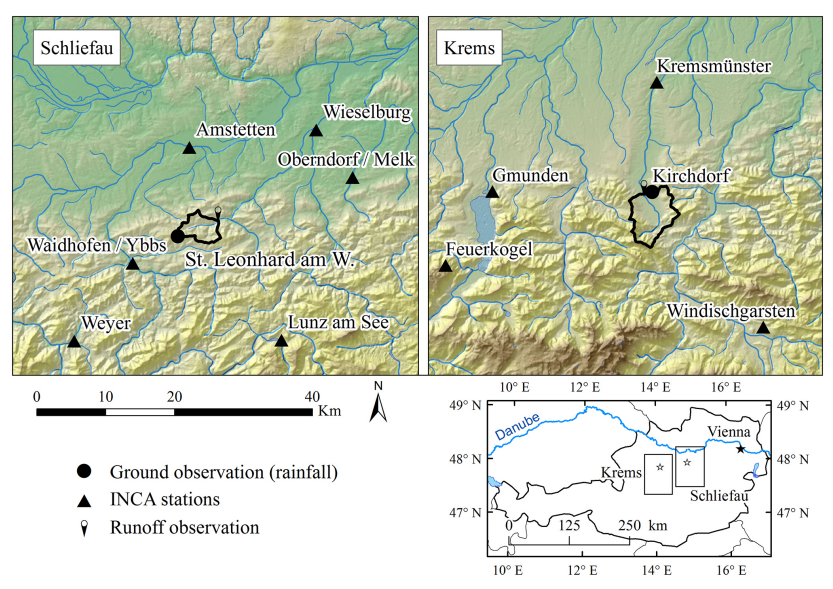

Figure 4. Schliefau and Krems catchments and location of meteorological stations. Note that ground observation of rainfall is not part of the INCA stations network.

Table 4. Characteristics of the study catchments (BMLFUW, 2007; BMLFUW, 2009).

\begin{tabular}{lll}
\hline & Schliefau & Krems \\
\hline Basin area $\left(\mathrm{km}^{2}\right)$ & 17.9 & 38.4 \\
Mean elevation $(\mathrm{m})$ & 608 & 598 \\
Elevation range (m) & $390-818$ & $413-1511$ \\
Mean annual precipitation $(\mathrm{mm})$ & 1390 & 1345 \\
Mean annual runoff $\left(\mathrm{m}^{3} \mathrm{~s}^{-1}\right)$ & 0.38 & 1.12 \\
\hline
\end{tabular}

$110 \mathrm{~km}$ south-west of the Austrian capital of Vienna and covers an area of $17.9 \mathrm{~km}^{2}$ with a mean elevation of $608 \mathrm{~m}$ a.s.1. About $55 \%$ of the area is covered by grassland and meadows, $40 \%$ by coniferous forest and $5 \%$ by mixed forest. The underlying geology is dominated by marl and sandstone. The Krems catchment is located about $170 \mathrm{~km}$ south-west of Vienna and covers an area of $38.4 \mathrm{~km}^{2}$ with a mean elevation of $598 \mathrm{~m}$ a.s.l. The topography is more heterogeneous, with an elevation range of 413-1511 ma.s.l., compared to 390$818 \mathrm{~m}$ a.s.l. in the Schliefau catchment. Approximately $46 \%$ of the area is covered by grassland and meadows, $48 \%$ by mixed forest, $4 \%$ by settlements and $2 \%$ by coniferous forest. On a long-term basis, in both catchments, the highest runoff can be expected during snowmelt in spring, the lowest runoff in summer and autumn until October. Figure 4 shows a map of the catchments and Table 4 summarises important characteristics of the study areas.

\subsection{Meteorological database}

Generally, two different rainfall time series are used. Ground observations of rainfall are available from the station St. Leonhard am Walde (Schliefau catchment) and Kirchdorf (Krems catchment), both located in the proximity of the catchments (Fig. 4). Additionally, areal rainfall data from the
INCA system (Integrated Nowcasting through Comprehensive Analysis; Haiden et al., 2011) are used. INCA is the operational nowcasting and analysis application developed and run by the Central Institute for Meteorology and Geodynamics of Austria (ZAMG); it is also used for the majority of real-time flood forecasting systems in Austria (Stanzel et al., 2008). For the present study, analysis fields derived from observations are used (nowcasting fields are not used). Rainfall in INCA is determined by a nonlinear spatial interpolation of rain-gauge values, in which the radar field is used as a spatial structure function. In addition an elevation correction is applied (Haiden and Pistotnik, 2009). The stations used for the interpolation of the INCA-rainfall fields are shown as triangles in Fig. 4. Note that the stations St. Leonhard am Walde and Kirchdorf are not included in the INCA analysis, since they are operated by a different institution. The rainfall fields from the INCA system cover the test basins in a spatial resolution of $1 \mathrm{~km}^{2}$. From the spatial data set, mean catchment rainfall values are obtained by calculating areaweighted means from the intersecting grid cells.

Potential evapotranspiration input is calculated with a temperature and potential radiation method (Hargreaves and Samani, 1982).

\subsection{Simulation periods}

Runoff and rainfall data are available for the period 20062009 in a temporal resolution of $60 \mathrm{~min}$, which is also the modelling time step. The virtual experiments are performed for a period of 4.5 months (15 May-30 September 2006) resulting in 3336 time steps being evaluated. As described in Sect. 2.3.2, different model calibration and simulation experiments are performed. An overview of these experiments is given in Table 5.

\section{Results and discussions}

\subsection{Virtual experiments}

In the virtual experiments it could be shown that the invertibility of the model equations is given. Using all 20000 simulated hydrographs from the Monte Carlo runs, where the parameters were varied stochastically, the observed rainfall time series could be identically reproduced by the inverse model. In addition to the rainfall, all fluxes and system states were also identical in the forward and inverse model runs.

For the second set of virtual experiments, station data from the Schliefau catchment with model parameters of $\operatorname{Exp}_{3}$ (see Table 5) were used as driving input in the forward model, and the resulting runoff simulation was used as input into the inverse model. To these resulting runoff simulations, however, noise with different magnitudes was added beforehand.

Depending on the magnitude of noise added to the runoff input time series, the inferred precipitation rates differ from the observed values, as is shown in Table 6. Without any 
Table 5. Overview of the model calibration and simulations experiments with observed input data. $P_{\text {obs }}$ and $P_{\text {Inca }}$ refer to the rainfall from the station observations and the INCA system.

\begin{tabular}{|c|c|c|c|c|c|c|}
\hline & \multicolumn{4}{|c|}{ Jun-Sep in year } & \multirow{2}{*}{$\begin{array}{c}\text { Driving input } \\
\text { (forward/inverse model) }\end{array}$} & \multirow[t]{2}{*}{ Purpose } \\
\hline & 2006 & 2007 & 2008 & 2009 & & \\
\hline $\begin{array}{l}\operatorname{Exp}_{1} \\
\operatorname{Exp}_{2} \\
\operatorname{Exp}_{3}\end{array}$ & $\begin{array}{l}\text { calib. } \\
\text { calib. } \\
\text { calib. }\end{array}$ & $\begin{array}{l}\text { valid. } \\
\text { calib. } \\
\text { calib. }\end{array}$ & $\begin{array}{l}\text { valid. } \\
\text { valid. } \\
\text { calib. }\end{array}$ & $\begin{array}{l}\text { valid. } \\
\text { valid. } \\
\text { valid. }\end{array}$ & $\begin{array}{l}P_{\mathrm{obs}} / Q \\
P_{\mathrm{obs}} / Q \\
P_{\mathrm{obs}} / Q\end{array}$ & $\begin{array}{l}\text { Influence of different calibration periods } \\
\text { on simulations }\end{array}$ \\
\hline $\operatorname{Exp}_{4}$ & calib. & calib. & calib. & valid. & $P_{\mathrm{obs}} / Q+10 \%$ & Influence of different runoff $Q$ on simulations \\
\hline $\operatorname{Exp}_{5}$ & calib. & calib. & calib. & valid. & $P_{\text {Inca }} / Q$ & Influence of different rainfall input on simulations \\
\hline $\operatorname{Exp}_{6}$ & \multicolumn{4}{|c|}{$\begin{array}{l}\text { Parameters from } \mathrm{Exp}_{3} \text {, } \\
\text { but different initial conditions }\end{array}$} & $P_{\mathrm{obs}} / Q$ & Influence of cold states on simulations \\
\hline
\end{tabular}

Table 6. Correlation (CORR), mean bias and mean squared error (MSE) for different temporal aggregation lengths between observed and inferred precipitation of the virtual experiments in which different magnitudes of noise were added to the input runoff data. These are indicated with the noise scaling factor.

\begin{tabular}{lrrr|rrr|rrr}
\hline \multirow{2}{*}{ Noise scaling factor } & \multicolumn{3}{c|}{ CORR (-) } & \multicolumn{3}{c|}{ Mean bias (mm) } & \multicolumn{2}{c}{ MSE (mm $\left.^{2}\right)$} \\
\cline { 2 - 8 } & 1 h sums & 6h sums & 24h sums & 1 h sums & 6h sums & 24h sums & 1 h sums & 6h sums & 24h sums \\
\hline $0 \%$ & 1.000 & 1.000 & 1.000 & 0.000 & 0.000 & 0.000 & 0.000 & 0.000 & 0.000 \\
$1 \%$ & 0.994 & 0.999 & 1.000 & -0.001 & -0.007 & -0.028 & 0.011 & 0.016 & 0.015 \\
$2 \%$ & 0.982 & 0.998 & 1.000 & -0.003 & -0.015 & -0.060 & 0.034 & 0.051 & 0.043 \\
$5 \%$ & 0.921 & 0.991 & 0.999 & -0.007 & -0.040 & -0.160 & 0.154 & 0.300 & 0.230 \\
$10 \%$ & 0.819 & 0.977 & 0.998 & -0.013 & -0.079 & -0.316 & 0.408 & 0.770 & 0.556 \\
\hline
\end{tabular}

noise the observed rainfall is reproduced exactly. With increasing noise a deterioration of the model performance is evident. Temporal aggregation leads to an increase in the correlation values, since the resulting noise in the inferred precipitation rates are smoothed out. The mean observed precipitation rate for the evaluated period in these virtual experiments is $0.21 \mathrm{~mm}$ for hourly precipitation, $1.26 \mathrm{~mm}$ for the $6 \mathrm{~h}$ sums and $5.03 \mathrm{~mm}$ for the daily precipitation rates. Based on these values, the mean quantitative bias ranges between -0.6 and $-6.3 \%$ relative to the mean observed rainfall, depending on the added noise scaling factor of $1-10 \%$. The inferred precipitation totals are higher, compared to the observed values, since the noise also leads to a quantitative bias between the runoff simulation of the inverse model and the runoff used as input. From the results it is clear that the inferred precipitation rates are sensitive to potential short-term errors in discharge measurements. Especially for the case in which the noise scaling factor was set to $10 \%$, assuming large short-term errors, the inverse model is not able to reproduce the disturbed input time series. This is also evident from the mean squared error values. The noise with a scaling factor of $10 \%$, however, leads to a strongly perturbed runoff time series. Also the forward model would not be able to reproduce this runoff time series with the given precipitation in a reasonable manner.

\subsection{Forward model: parameter calibration and validation of the different simulation experiments}

A precondition for the application of the inverse model is that the observed runoff characteristics of the catchment be reproduced reasonably by the forward model, since these parameters are also used in the inverse model. The following section therefore presents the runoff simulations of the forward model, based on the different simulation experiments $\operatorname{Exp}_{1}-\operatorname{Exp}_{5}$.

The model performance for different periods of the forward model, expressed by NSE and the mean bias between simulated and observed runoff in percent of observed runoff is shown in Table 7. As mentioned before, only the months June, July, August and September of the single years are used.

With the exception of $\operatorname{Exp}_{5}$, the NSE values of the calibration periods are larger than 0.8 in both catchments. The highest NSE values of 0.87 (Schliefau) and 0.88 (Krems) are found for $\operatorname{Exp}_{1}$. The short calibration period used in this experiment (only June-September 2006 are used; see Table 5) enables a good fitting of the model parameters to the runoff observations. In consequence the largest deterioration of the model performance in the validation period is evident for $\operatorname{Exp}_{1}$ for both catchments, since runoff conditions differ from calibration. For the other experiments the differences 
Table 7. Model performance for the different simulation experiments and the two catchments of the forward model, expressed by NSE and the mean bias between simulated and observed runoff in percent of observed runoff for different periods. Only the months June-September are evaluated.

\begin{tabular}{|c|c|c|c|c|c|c|c|}
\hline & & \multicolumn{3}{|c|}{$\operatorname{NSE}(-)$} & \multicolumn{3}{|c|}{ mean Bias (\%) } \\
\hline & & Calib. & Valid. & 2006-2009 & Calib. & Valid. & 2006-2009 \\
\hline \multirow{5}{*}{$\frac{\vec{\pi}}{\stackrel{\Xi}{0}}$} & $\operatorname{Exp}_{1}$ & 0.872 & 0.814 & 0.822 & 4.8 & 8.7 & 7.8 \\
\hline & $\operatorname{Exp}_{2}$ & 0.858 & 0.819 & 0.832 & 11.4 & -0.8 & 3.9 \\
\hline & $\operatorname{Exp}_{3}$ & 0.812 & 0.837 & 0.828 & 1.5 & 0.1 & 0.9 \\
\hline & $\operatorname{Exp}_{4}$ & 0.814 & 0.840 & 0.830 & -4.4 & -8.3 & -5.9 \\
\hline & $\operatorname{Exp}_{5}$ & 0.738 & 0.715 & 0.728 & 2.1 & -4.9 & -0.6 \\
\hline \multirow{5}{*}{ 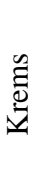 } & $\operatorname{Exp}_{1}$ & 0.879 & 0.740 & 0.763 & -9.4 & 1.2 & -1.4 \\
\hline & $\operatorname{Exp}_{2}$ & 0.849 & 0.851 & 0.851 & -0.3 & -8.6 & -4.8 \\
\hline & $\operatorname{Exp}_{3}$ & 0.842 & 0.855 & 0.851 & -3.2 & -8.0 & -4.8 \\
\hline & $\operatorname{Exp}_{4}$ & 0.845 & 0.859 & 0.854 & -6.1 & -11.5 & -7.9 \\
\hline & $\operatorname{Exp}_{5}$ & 0.748 & 0.815 & 0.787 & 3.7 & -2.8 & 1.5 \\
\hline
\end{tabular}

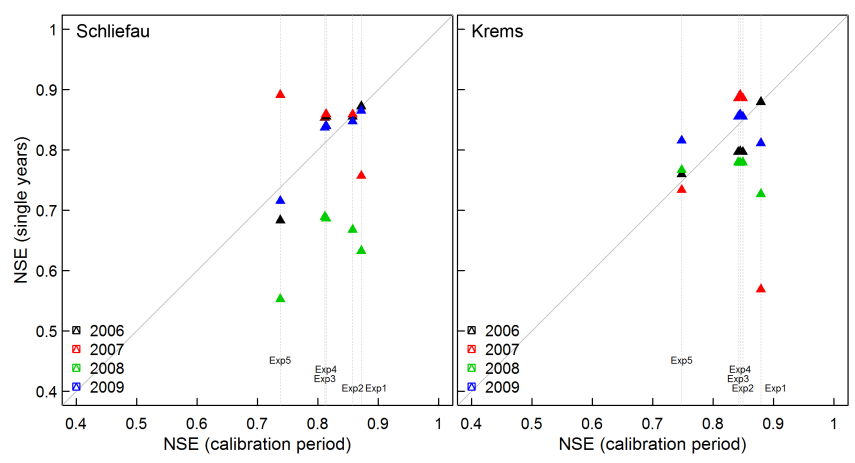

Figure 5. Nash-Sutcliffe efficiency (NSE) of the forward model for the calibration periods versus single years for the two study areas.

in the NSE values between calibration and validation periods are less pronounced, with some experiments showing higher model performance in the validation period. In Exp5 INCA rainfall data are used as driving input for the simulations. The main intention of $\operatorname{Exp}_{5}$ is to evaluate the influence of a different rainfall input on the calibration of the model parameters and in consequence also on the inverse rainfall. For both catchments, the NSE values of the forward model are mostly significantly lower, also compared to $\operatorname{Exp}_{3}$ which has the same calibration and validation periods. Although INCA uses a complex interpolation scheme, also incorporating radar data and a rainfall-intensity-dependent elevation correction (Haiden et al., 2011; Haiden and Pistotnik, 2009), it seems that the data set has deficits representing catchment rainfall compared to the station observations in the proximity of the catchments. This can be explained by the larger distance of about $10-35 \mathrm{~km}$ of the INCA stations from the catchment (see Fig. 4). Note that the ground observations in the proximity of the catchments are not used in the interpolation process for the INCA-rainfall fields, as they belong to a monitoring network operated by a different institution.
For $\operatorname{Exp}_{1}-\mathrm{Exp}_{3}$, the NSE-values for the period 2006-2009 show that the overall model performance is fairly stable and comparable, independent of the calibration length. The NSE values are larger than 0.82 , with the exception of $\operatorname{Exp}_{1}$ in the Krems catchment. Although the calibration lengths and periods in $\operatorname{Exp}_{2}$ and $\operatorname{Exp}_{3}$ differ, identical model parameters were found for the Krems catchment in the optimisation for both simulation experiments. As a consequence the model performance is identical in these two experiments for the period 2006-2009.

The mean bias does not show a clear pattern and seems to be independent from the calibration period and length. In the Schliefau catchment observed runoff is overestimated by $7.8-0.9 \%$ and underestimated by -1.4 to $-4.8 \%$ in the Krems catchment for the period 2006-2009, depending on the simulation $\operatorname{Exp}_{1}-\operatorname{Exp}_{3}$. Overall, the calculated bias between observed and simulated runoff is in reasonable bounds.

In $\operatorname{Exp}_{4}$ the observed runoff is increased by $10 \%$, mainly to evaluate the influence of possible streamflow errors on the simulations and the inverse rainfall. The same calibration periods were used as in $\operatorname{Exp}_{3}$, with station observations as driving input into the model. The NSE of $\operatorname{Exp}_{4}$ is comparable to $\operatorname{Exp}_{1}, \operatorname{Exp}_{2}$ and $\operatorname{Exp}_{3}$. The mean bias in $\operatorname{Exp}_{4}$ however becomes larger in both catchments. The observed runoff is now also underestimated in the Schliefau catchment, what is not surprising since observed runoff was increased.

Figure 5 shows the NSE values of the forward model for the calibration periods of every simulation experiment versus the single year's performance for the two study areas.

For $\operatorname{Exp}_{1}$ a significant larger spread in the model performance within the single years is evident. In $\operatorname{Exp}_{1}$ only 2006 was used for calibration. As a consequence, especially for the Krems catchment, the model performance is lower in the years 2007-2009, compared to $\operatorname{Exp}_{2}$ and $\operatorname{Exp}_{3}$. In the short calibration period of 2006 the model parameters are overfitted to the observations. If the conditions in the catchment are 


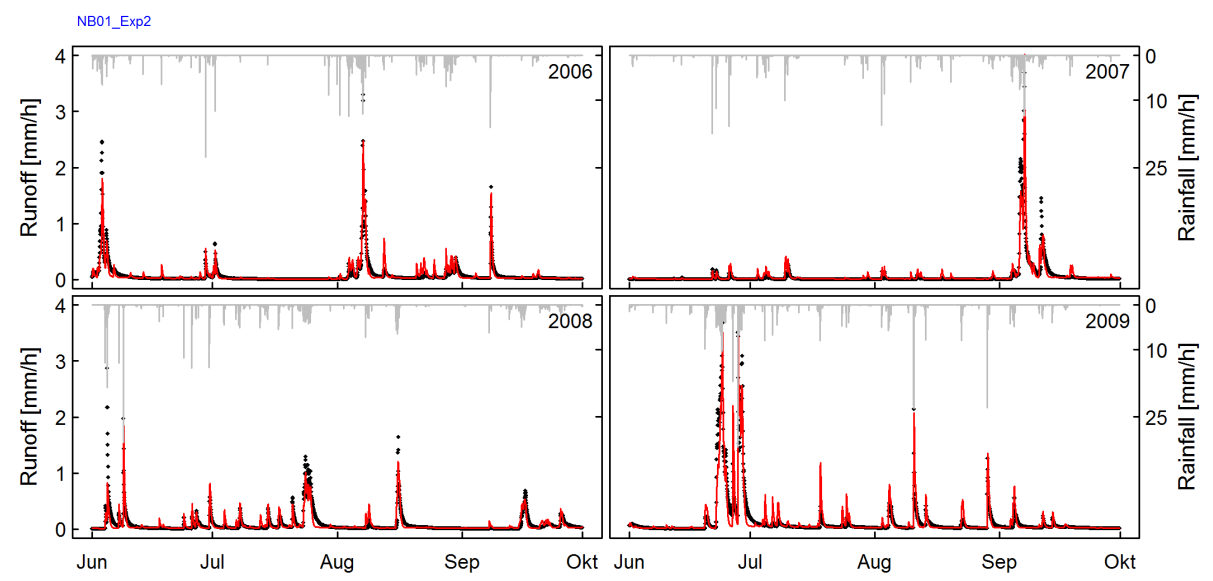

Figure 6. Schliefau catchment: observed (black points) and simulated (red) runoff of $\operatorname{Exp}_{2}$.

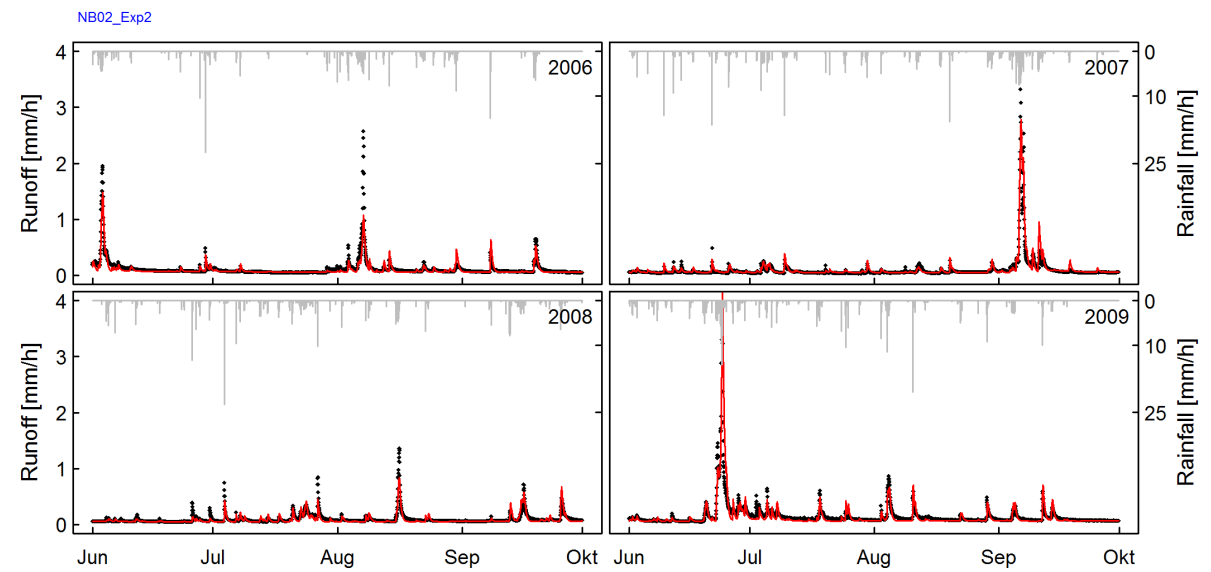

Figure 7. Krems catchment: observed (black points) and simulated (red) runoff of $\operatorname{Exp}_{2}$.

different from the calibration period, the model performance can be expected to deteriorate, as has been shown before (e.g. Kling, 2015; Seibert, 2003), and explains the findings. However, for $\operatorname{Exp}_{2}-\mathrm{Exp}_{4}$ the model performance is stable for the single years, as for 2009, which was not used for calibration in any simulation experiment. In contrast to the Krems area, a large spread in the model performance of the single years for $\operatorname{Exp}_{5}$ is visible in the Schliefau catchment. The reason is not clear and may be explained by the changing availability of station data for the INCA rainfall in the single years. We can, however, not verify this hypothesis, since we do not have access to the data sets. In the Schliefau catchment low NSE values are calculated for the year 2008 for all simulation experiments. In the beginning of June a flood was observed (Fig. 6), which is not simulated in the model runs and explains the lower NSE values in this year. Excluding this event in the performance calculations would result in a significantly higher NSE of 0.84 for $\operatorname{Exp}_{1}$ for the year 2008, compared to 0.63 when the flood event is included in the calculation.
Figures 6 (Schliefau) and 7 (Krems) exemplarily show the runoff simulations based on the results of $\operatorname{Exp}_{2}$. For both catchments, the dynamics and variability of the runoff observations are mostly reproduced in a satisfactory manner. However, a tendency is visible, which is that larger floods are underestimated in the simulations.

All simulations are performed with a lumped model setup. Consequently, heterogeneity in geology and land use within the catchment are not considered in the parameter estimation. Also taking this into consideration, it can be concluded that the general responses of the catchment to rainfall input are captured appropriately by the forward model. Only for $\operatorname{Exp}_{1}$, with the very short calibration period, is a larger deterioration of the model performance in the validation period and a larger spread in independent years evident. It is therefore justified to calculate areal rainfall from runoff using the inverted forward model, including the optimised parameters. 


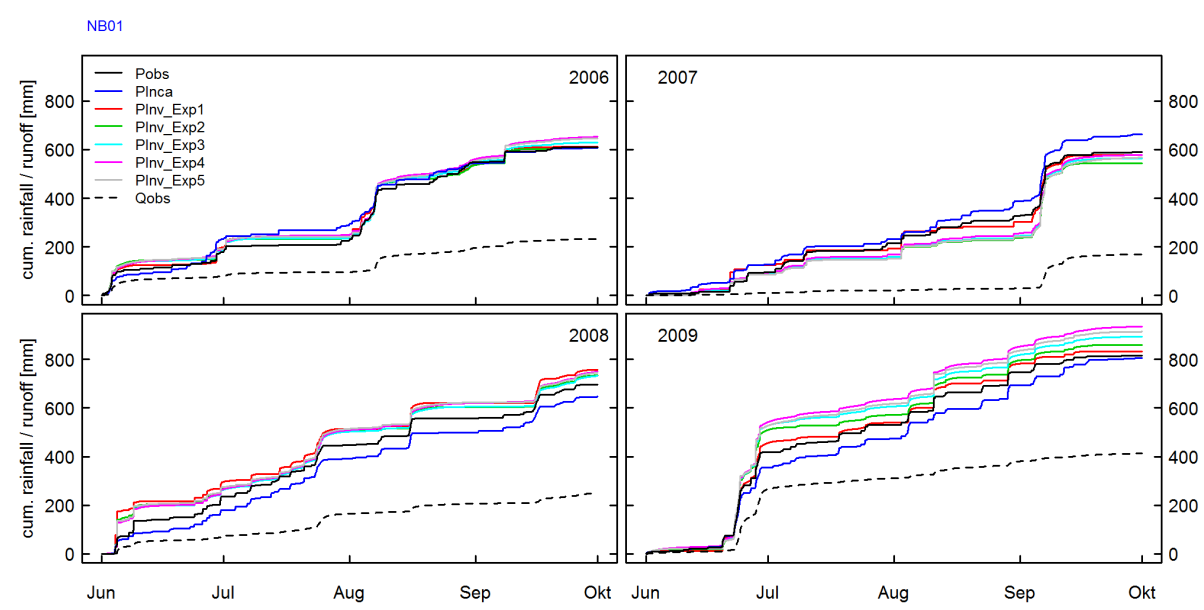

Figure 8. Schliefau catchment: cumulative rainfall curves for observed rainfall $\left(P_{\text {obs }}\right)$, INCA rainfall $\left(P_{\text {Inca }}\right)$ and the inverse rainfall of $\operatorname{Exp}_{1}-\operatorname{Exp}_{5}\left(P_{\text {inv }}\right)$. Cumulative sums of observed runoff are shown as dashed black lines.

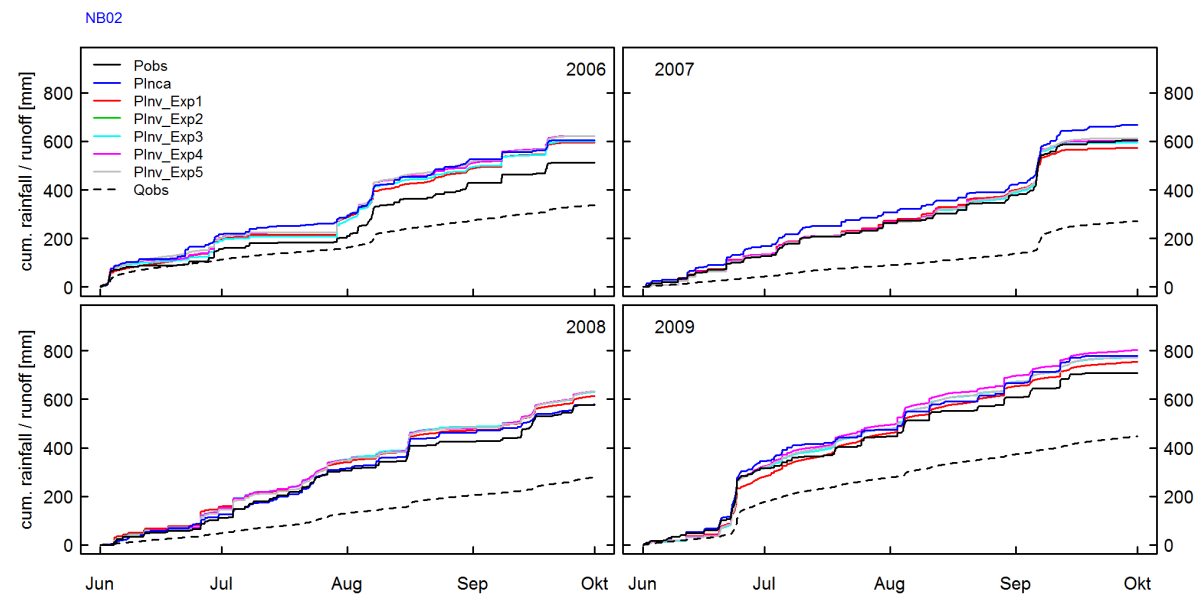

Figure 9. Krems catchment: cumulative rainfall curves for observed rainfall $\left(P_{\mathrm{obs}}\right)$, INCA rainfall $\left(P_{\text {Inca }}\right)$ and the inverse rainfall of Exp $1^{-}$ Exp5. Cumulative sums of observed runoff are shown as dotted black lines.

\subsection{Inverse model}

For the evaluation of the simulated rainfall from the inverse model $\left(P_{\text {inv }}\right)$ we will compare the calculated values with observed station data $\left(P_{\mathrm{obs}}\right)$ of St. Leonhard (Schliefau catchment) and Kirchdorf (Krems catchment) and the rainfall values from the INCA-system ( $\left.P_{\text {Inca }}\right)$. In the following, cumulative rainfall sums and the correlation and bias between simulated and observed rainfall are presented. Additionally, the rainfall and runoff simulations of a flood event and the influence of cold system states on the simulations are shown.

\subsubsection{Cumulative rainfall sums}

Figures 8 and 9 show the cumulative curves of the observed rainfall $\left(P_{\text {obs }}\right)$, INCA rainfall $\left(P_{\text {Inca }}\right)$ and the inverse rainfall $\left(P_{\text {inv }}\right)$ of the simulation experiments $\operatorname{Exp}_{1}-\operatorname{Exp}_{5}$ for the Schliefau and Krems catchments. Additionally, the cumula- tive observed runoff $\left(Q_{\text {obs }}\right)$ is shown as a dashed line. Note that for the Krems catchment (Fig. 9) the rainfall curves of $\operatorname{Exp}_{2}$ and $\operatorname{Exp}_{3}$ are identical, since the model parameters are also identical in these simulation experiments.

The cumulative sums of the inverse rainfall and the observation-based rainfall realisations $P_{\text {obs }}$ and $P_{\text {Inca }}$ mostly show very similar temporal dynamics. Although large deviations are sometimes evident for both catchments, the deviations of the cumulative curves of $P_{\text {Inca }}$ and the different inverse rainfalls $\left(P_{\text {inv }}\right)$ from the cumulative curves of the ground observation $\left(P_{\mathrm{obs}}\right)$ are mostly of similar magnitude.

The inverse rainfall curves of $\operatorname{Exp}_{1}-\operatorname{Exp}_{5}$ of the two catchments do not exhibit substantial differences, although different calibration periods and setups were used. At the beginning of June 2008 a flood was observed in the Schliefau catchment, which was underestimated in the forward simulation presumably due to inadequate representation of the storm event in the rainfall observations (see runoff simula- 
Table 8. Correlation between different rainfall realisations, evaluated for different periods and for $1 \mathrm{~h}$ and $24 \mathrm{~h}$ sums. $\left(P_{\text {obs}}\right.$ : ground observation, $P_{\text {inv }}$ : inverse rainfall from $\operatorname{Exp}_{1}$ to $\operatorname{Exp}_{5}, P_{\text {Inca }}$ : INCA rainfall).

\begin{tabular}{|c|c|c|c|c|c|c|c|c|c|c|c|}
\hline & & \multicolumn{5}{|c|}{ CORR: $1 \mathrm{~h}$ sums } & \multicolumn{5}{|c|}{ CORR: 24 h sums } \\
\hline & & \multicolumn{3}{|c|}{$P_{\mathrm{obs}}-P_{\mathrm{inv}}$} & \multirow{2}{*}{$\frac{P_{\text {Inca }}-P_{\text {inv }}}{2006-2009}$} & \multirow{2}{*}{$\frac{P_{\text {obs }}-P_{\text {Inca }}}{2006-2009}$} & \multicolumn{3}{|c|}{$P_{\mathrm{obs}}-P_{\mathrm{inv}}$} & \multirow{2}{*}{$\begin{array}{c}P_{\text {Inca }}-P_{\text {inv }} \\
2006-2009\end{array}$} & \multirow{2}{*}{$\frac{P_{\text {obs }}-P_{\text {Inca }}}{2006-2009}$} \\
\hline & & Calib. & Valid. & 2006-2009 & & & Calib. & Valid. & 2006-2009 & & \\
\hline \multirow{5}{*}{ 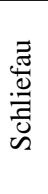 } & $\operatorname{Exp}_{1}$ & 0.706 & 0.460 & 0.504 & 0.251 & \multirow[t]{5}{*}{0.463} & 0.935 & 0.857 & 0.871 & 0.802 & \multirow[t]{5}{*}{0.928} \\
\hline & $\operatorname{Exp}_{2}$ & 0.572 & 0.540 & 0.549 & 0.290 & & 0.939 & 0.895 & 0.914 & 0.840 & \\
\hline & $\operatorname{Exp}_{3}$ & 0.515 & 0.567 & 0.534 & 0.284 & & 0.913 & 0.929 & 0.918 & 0.845 & \\
\hline & $\mathrm{Exp}_{4}$ & 0.515 & 0.558 & 0.530 & 0.283 & & 0.910 & 0.928 & 0.917 & 0.843 & \\
\hline & $\operatorname{Exp}_{5}$ & 0.514 & 0.545 & 0.524 & 0.276 & & 0.916 & 0.927 & 0.920 & 0.842 & \\
\hline \multirow{5}{*}{ 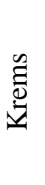 } & $\operatorname{Exp}_{1}$ & 0.622 & 0.430 & 0.478 & 0.394 & \multirow[t]{5}{*}{0.469} & 0.880 & 0.871 & 0.871 & 0.847 & \multirow[t]{5}{*}{0.931} \\
\hline & $\operatorname{Exp}_{2}$ & 0.437 & 0.602 & 0.517 & 0.445 & & 0.907 & 0.910 & 0.909 & 0.889 & \\
\hline & $\operatorname{Exp}_{3}$ & 0.493 & 0.581 & 0.517 & 0.445 & & 0.896 & 0.936 & 0.909 & 0.889 & \\
\hline & $\operatorname{Exp}_{4}$ & 0.494 & 0.577 & 0.517 & 0.445 & & 0.896 & 0.936 & 0.909 & 0.892 & \\
\hline & $\operatorname{Exp}_{5}$ & 0.473 & 0.593 & 0.503 & 0.445 & & 0.884 & 0.936 & 0.901 & 0.888 & \\
\hline
\end{tabular}

tion in Fig. 6, lower left). Larger rainfall intensities are therefore calculated by the inverse for this period, leading to the larger deviations between the cumulative sums of $P_{\mathrm{obs}}$ and $P_{\text {inv }}$ of $\operatorname{Exp}_{1}-\operatorname{Exp}_{5}$ as shown in Fig. 8 (lower left). In the Schliefau catchments larger differences between $\operatorname{Exp}_{1}$ and Exp $_{5}$ occur in the year 2009 (Fig. 8, lower right). Here, in the second half of June, a period of strong rainfall is evident, which also led to a series of floods in the catchment (see also the hydrographs in Fig. 6). The rainfall sums originating from these high flows were calculated differently in the inverse models, depending on the simulation experiment. In consequence, the inverse rainfall curves differ from July onwards. In 2009, which was the wettest summer in both catchments, the highest inverse rainfall sums were found for Exp4. This is what could be expected, since the observed runoff was increased by $10 \%$ in this simulation experiment. However, in the other years $\operatorname{Exp}_{4}$ does not necessarily show the largest inverse rainfall sums. The optimised model parameters in $\operatorname{Exp}_{4}$, which control evapotranspiration, were limiting actual evapotranspiration from the model to fulfil the water balance, since $P_{\mathrm{obs}}$ was not changed. In the second half of June 2009, however, during the flood events with low evapotranspiration, the higher runoff values used as input show a clearer signal in the inverse rainfall sums.

The large difference between cumulative rainfall and runoff curves highlight the importance of actual evapotranspiration $\left(\mathrm{ET}_{\mathrm{a}}\right)$ in the catchments. For the Schliefau catchment the mean observed rainfall for the summer months of 2006-2009 is $678 \mathrm{~mm}$, and $266 \mathrm{~mm}$ are observed in the mean for runoff. Neglecting storage effects, a mean actual evapotranspiration of $412 \mathrm{~mm}$ can be calculated from the water balance. Over $60 \%$ of rainfall is therefore lost to evapotranspiration. The mean actual evapotranspiration from the inverse model, depending on the simulation experiment, ranges from 352 to $362 \mathrm{~mm}$ and is lower compared to the $\mathrm{ET}_{\mathrm{a}}$ calculated from the water balance. In the Krems catchment a mean runoff of $334 \mathrm{~mm}$ and rainfall of $600 \mathrm{~mm}$, resulting in an actual evapotranspiration of $266 \mathrm{~mm}$, is calculated. Although lower compared to Schliefau, nearly $45 \%$ of the rainfall is lost to the atmosphere. The mean actual evapotranspiration from the inverse model, again depending on the simulation experiment, ranges from 276 to $310 \mathrm{~mm}$. If the model would not capture $\mathrm{ET}_{\mathrm{a}}$ adequately, the cumulative rainfall curves would not follow the observations so closely.

On the basis of the different cumulative rainfall sums it can be concluded that on a longer temporal basis the inverse model is capable of simulating the catchment rainfall from runoff observations. This is also the case for independent validation periods and years, which were not used in the calibration. The results from the different simulation experiments do not differ substantially and show close correspondence to the observed data, except for a single summer in the Schliefau catchment.

\subsubsection{Correlation and bias between simulated and observed rainfall}

The performance of the inverse model expressed by the correlation coefficient is used to measure the model's ability to reproduce timing and shape of observed rainfall values. It is independent of a possible quantitative bias. In the introduction, the difficulties involved in the quantitative measurement of rainfall were discussed. It can however be assumed that a qualitative measurement, e.g. if it rains or not, will be more reliable. Table 8 shows the correlation values between ground observations and the different inverse rainfall realisations $\left(P_{\text {obs }}-P_{\text {inv }}\right)$ and between ground observations and INCA rainfall ( $\left.P_{\text {obs }}-P_{\text {Inca }}\right)$ for different periods and temporal aggregation lengths.

The highest correlation values between $P_{\mathrm{obs}}$ and $P_{\text {inv }}$ for the $1 \mathrm{~h}$ sums and calibration period are found for $\operatorname{Exp}_{1}$ with 0.71 (Schliefau) and 0.62 (Krems). For the other experiments the correlation values in the calibration period are lower 
(0.51-0.57 in the Schliefau area and 0.44-0.49 in the Krems catchment). For the validation period the correlation between $P_{\text {obs }}$ and $P_{\text {inv }}$ deteriorates in $\operatorname{Exp}_{1}$. For the remaining experiments, however, the correlation in the validation period is mostly higher, compared to calibration. This agrees with the finding from the forward simulation results, since better model performance in the validation period of the forward model also leads to a higher correlation between $P_{\text {obs }}$ and $P_{\text {inv }}$. For the temporally aggregated $24 \mathrm{~h}$ sums the correlation values generally increase for the calibration and validation periods.

For the period 2006-2009 and $1 \mathrm{~h}$ sums, the lowest correlation values between $P_{\mathrm{obs}}$ and $P_{\mathrm{inv}}$ are found for the simulation results of $\operatorname{Exp}_{1}$ in both catchments. The highest correlation values are found for $\operatorname{Exp}_{2}$ in the Schliefau catchment and $\operatorname{Exp}_{2}-\operatorname{Exp}_{4}$ in the Krems catchment. This agrees with the performance of the forward model presented in Sect. 4.2. The correlation of the $1 \mathrm{~h}$ sums between $P_{\mathrm{obs}}$ and $P_{\mathrm{inv}}$ is rather weak. However, the correlation between $P_{\text {obs }}$ and $P_{\text {inv }}$ is higher for all simulation experiments and $1 \mathrm{~h}$ sums compared to the correlation between $P_{\text {obs }}$ and $P_{\text {Inca }}$. This is interesting, since $P_{\text {Inca }}$ is based on station rainfall observations and $P_{\text {inv }}$ is indirectly derived from runoff through simulations. With temporal aggregation the correlation values generally increase significantly for all combinations. Small differences or timing errors in the $1 \mathrm{~h}$ sums are eliminated with temporal aggregation. This is also the case for the INCA data.

For $\operatorname{Exp}_{1}-\mathrm{Exp}_{4}$, the model parameters used for the forward and inverse models were automatically calibrated using the ground observation $P_{\mathrm{obs}}$ as input. It could therefore be concluded that the model parameters are conditioned by $P_{\text {obs }}$ and that in consequence the fairly good agreement between $P_{\text {obs }}$ and $P_{\text {inv }}$ originates from this conditioning. Based on this hypothesis, calibrating the model with INCA data should lead to a better agreement between the INCA data and the corresponding inverse rainfall and a deterioration of the correlation between station data and inverse rainfall. For $\operatorname{Exp}_{5}$, the forward model was therefore calibrated with INCA data and the resulting parameter set was then used to calculate the inverse rainfall. The correlation between $P_{\text {Inca }}$ and $P_{\text {inv }}$ for $\operatorname{Exp}_{5}$ is however not higher compared to the other simulation experiments and $\operatorname{Exp}_{3}$, which had the same calibration period. This excludes that the parameters are conditioned (at least for the rainfall simulations) by the input used for calibration. The comparison of $\operatorname{Exp}_{3}$ and $\operatorname{Exp}_{5}$ is critical and shows that the inverse model provides reasonable results in the case where the forward model is calibrated with rainfall data that are independent from the observed catchment rainfall: the forward model exhibits significantly lower NSE in $\operatorname{Exp}_{5}$ compared to $\operatorname{Exp}_{3}$, which is expected because the forward model is driven with the lower quality INCA rainfall in $\operatorname{Exp}_{5}$ (see Table 7). The correlation between $P_{\text {obs }}$ and $P_{\text {inv }}$ however suggests that $\operatorname{Exp}_{5}$ is comparably representative of the rainfall dynamics as $\operatorname{Exp}_{3}$.
The correlations between $P_{\text {Inca }}$ and $P_{\text {inv }}$ are generally very weak, with values ranging from 0.25 to 0.29 for the Schliefau catchment and from 0.39 to 0.445 for the Krems catchment.

For the period 2006-2009, the correlation between $P_{\text {obs }}$ and $P_{\text {inv }}$ for the $1 \mathrm{~h}$ sums ranges between 0.48 and 0.55 and is higher compared to the correlation between $P_{\text {obs }}$ and $P_{\text {Inca }}$. In contrast, Kirchner (2009) shows correlation values between simulated and observed rainfall of 0.81 and 0.88 for his two sites. The Schliefau and Krems catchments differ substantially in size, hydrological characteristics, land use and geology. The NSE values of the runoff simulations in Kirchner (2009) are higher, compared to the values presented here for the forward model. As a consequence the better performance in the rainfall simulations may be explained by the fact that the Kirchner (2009) model better reflects the catchment conditions leading to runoff.

For the $24 \mathrm{~h}$ sums and the period 2006-2009 we calculate a correlation of $0.87-0.92$, depending on the catchment and simulation experiment. Here, Kirchner (2009) shows correlations of 0.96 and 0.97 . Krier et al. (2012) present correlations between simulated and observed rainfall of 0.81-0.98, with a mean value of 0.91 for a total of 24 catchments, however only on the basis of data of a single year. The correlation in our results is therefore in the range of other studies. Unfortunately, Krier et al. (2012) do not present NSE values of the runoff simulations. It is therefore not possible to check the link between the performance of the forward model and rainfall simulations in their study.

Figure 10 shows the correlation between $P_{\mathrm{obs}}$ and $P_{\text {inv }}$ for the calibration periods of the simulation experiments $\operatorname{Exp}_{1}-$ $\operatorname{Exp}_{5}$ versus the correlation in single years for the two study areas. For the Schliefau catchment, the largest spread in the correlation values of the single years is found for $\operatorname{Exp}_{1}$, which also corresponds to the performance of the runoff simulations of the forward model. For $\operatorname{Exp}_{2}-\operatorname{Exp}_{5}$ a spread is also visible between the single years, but differences are smaller. For the years 2006, 2008 and 2009 the correlation values in the Krems catchment do not differ substantially. Here however the correlation for the year 2007 is very low, regardless of the simulation experiment. This may be explained by the comparatively dry summer of 2007. Also, in the Schliefau catchment the correlation values are mostly lower in 2007, compared to the other years.

Table 9 summarises the mean bias (in $\mathrm{mmh}^{-1}$ and $\mathrm{mm} \mathrm{d}^{-1}$ ) between different rainfall realisations, evaluated for different periods, and for $1 \mathrm{~h}$ and $24 \mathrm{~h}$ sums. Except for Exp 1 the bias is larger in the validation compared to the calibration periods.

For the period 2006-2009 and the Schliefau catchment, the bias between $P_{\text {inv }}$ and $P_{\mathrm{obs}}$ is mostly higher, compared to the bias between $P_{\text {Inca }}$ and $P_{\text {obs }}$. Only Exp 2 , with a mean bias of $0.07 \mathrm{~mm} \mathrm{~d}^{-1}$, has a comparable bias to that between $P_{\text {Inca }}$ and $P_{\text {obs }}$ of $0.02 \mathrm{~mm} \mathrm{~d}^{-1}$. Exp 2 also showed the highest performance in the runoff simulations concerning the NSE. In contrary, for the Krems catchment, the bias is lower between 


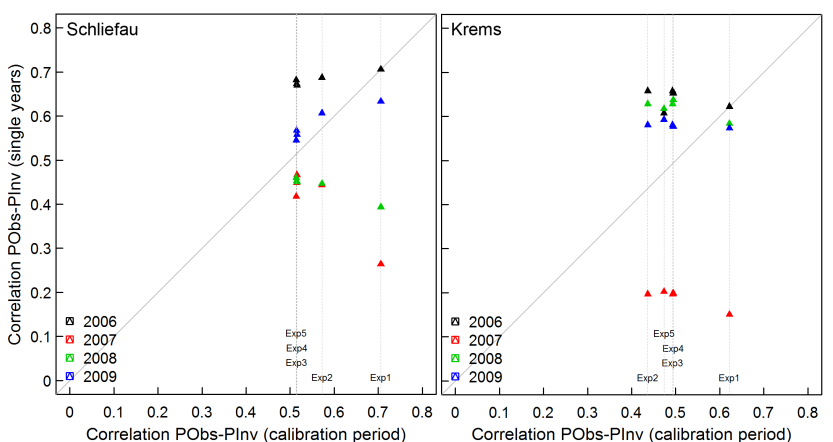

Figure 10. Correlation between $P_{\mathrm{obs}}$ and $P_{\text {inv }}$ for the calibration periods of the simulation experiments $\operatorname{Exp}_{1}-\operatorname{Exp}_{5}$ versus single years for the two study areas.

$P_{\text {inv }}$ and $P_{\text {obs }}$ for $\operatorname{Exp}_{1}-\mathrm{Exp}_{3}$, compared to $P_{\text {Inca }}$ and $P_{\text {obs }}$. For $\operatorname{Exp}_{1}-\operatorname{Exp}_{3}$ and the period 2006-2009 mean biases of $0.14 \mathrm{~mm} \mathrm{~d}^{-1}$ (Schliefau) and $0.36 \mathrm{~mm} \mathrm{~d}^{-1}$ (Krems) are calculated. As a comparison, Krier et al. (2014) published mean bias values between simulated and observed rainfall of -3.3 to $1.5 \mathrm{~mm} \mathrm{~d}^{-1}$ (mean $-0.35 \mathrm{~mm} \mathrm{~d}^{-1}$ ) for 24 catchments on the basis of a single year. From all simulation experiments, Exp $_{4}$ shows the largest bias, which is explained by the fact that runoff was increased in this experiment. Here the increased runoff clearly shows a signal in the inverse rainfall.

\subsubsection{Rainfall and runoff simulations for a flood event}

Figure 11 exemplarily illustrates the temporal development of the different rainfall realisations and runoff simulations for the highest flood event in the Krems catchment. Results from $\operatorname{Exp}_{3}$ are shown. Compared to $P_{\text {obs }}$ and $P_{\text {Inca }}$ the inverse rainfall $P_{\text {inv }}$ exhibits higher variability and higher intensities. The higher variability and oscillating nature of the inverse rainfall is explainable with the reaction of the inverse model to small fluctuations in runoff observations: in case of rising runoff observations, rainfall will be estimated by the inverse model. If the observed runoff decreases and the simulated runoff of the inverse model is larger than observed runoff, no inverse rainfall will be calculated, leading to the visible oscillations. Figure $11 \mathrm{~b}$ shows that the forward model, driven with $P_{\mathrm{obs}}$ as input, underestimates both flood peaks. The forward model, driven with the inverse rainfall, simulates the driven periods very well (Inverse $Q_{\text {sim }}$ ). However, especially, the falling limb after the second flood peak on 7 September 2007 is overestimated by the inverse model. In this period it is also visible that, in consequence, no rainfall is calculated by the inverse model, since simulated runoff is higher than observed runoff.

For a given time interval, the inverse model will yield an exact agreement between observed and simulated runoff, as long as there is a positive rainfall value $R_{t}$ to solve Eq. (5). This will be the case in periods of rising limbs of observed runoff (driven periods), as a rainfall value can be estimated,
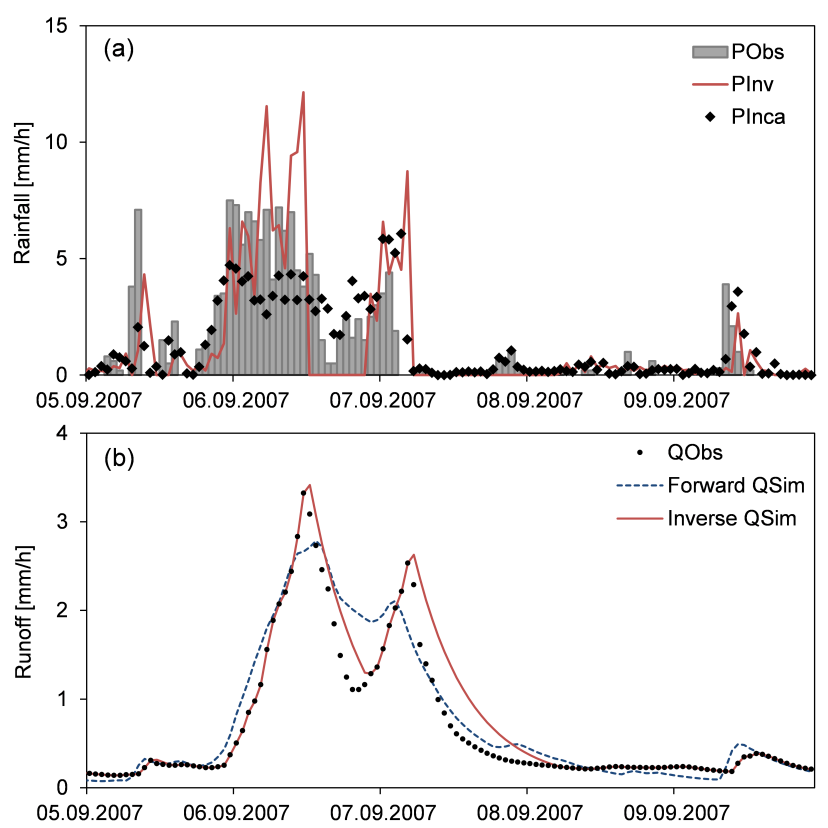

Figure 11. Krems catchment: temporal development of the different rainfall realisations (a) and runoff (b) for a flood event. Simulations originate from $\operatorname{Exp}_{3}$.

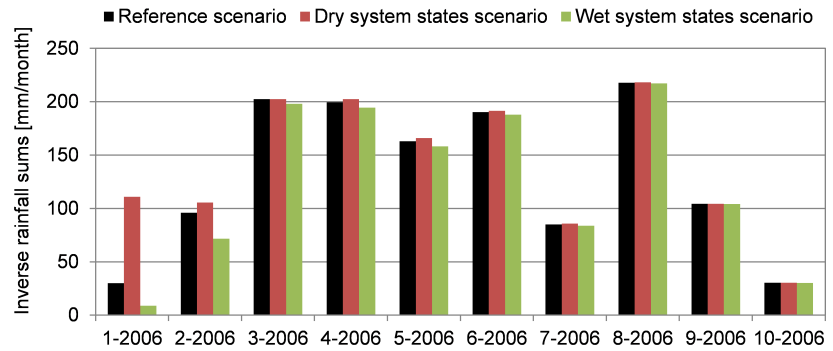

Figure 12. Krems catchment: monthly sums of inverse rainfall simulated in the scenarios "reference", "dry" and "wet" from Exp6.

which raises the simulated runoff value to match the observations. Conversely, in periods of observed falling limbs (nondriven periods) the simulated runoff will solely be a function of the model structure, its parameters and the antecedent system states, as negative rainfall values are ruled out beforehand. This explains why, in periods in which the simulated runoff is higher than the observed value, no rainfall is calculated by the inverse model.

\subsubsection{Influence of cold system states on the inverse rainfall $\left(\operatorname{Exp}_{6}\right)$}

To test the influence of cold states on the inverse rainfall simulations the simulation experiment $\operatorname{Exp}_{6}$ was performed. Three different cold states (reference, dry and wet system states) were thereby defined (see Sect. 2.3.2). Figure 12 exemplarily shows the results of $\operatorname{Exp}_{6}$ for the Krems catchment. 
Table 9. Mean Bias (in mm) between different rainfall realisations, evaluated for different periods and $1 \mathrm{~h}$ and $24 \mathrm{~h}$ sums.

\begin{tabular}{|c|c|c|c|c|c|c|c|c|c|c|c|}
\hline & & \multicolumn{5}{|c|}{ Mean bias: $1 \mathrm{~h}$ sums $\left(\mathrm{mm} \mathrm{h}^{-1}\right)$} & \multicolumn{5}{|c|}{ Mean bias: $24 \mathrm{~h}$ sums $\left(\mathrm{mm} \mathrm{d}^{-1}\right)$} \\
\hline & & Calib. & Valid. & $2006-2009$ & $\frac{P_{\text {inv }}-P_{\text {Inca }}}{2006-2009}$ & $\begin{array}{r}P_{\text {Inca }}-P_{\text {obs }} \\
2006-2009\end{array}$ & Calib. & Valid. & $2006-2009$ & $\frac{P_{\text {inv }}-P_{\text {Inca }}}{2006-2009}$ & $\frac{P_{\text {Inca }}-P_{\text {ob }}}{2006-2005}$ \\
\hline \multirow{3}{*}{ 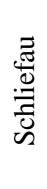 } & $\operatorname{Exp}_{1}$ & 0.001 & 0.007 & 0.006 & 0.005 & \multirow[t]{3}{*}{0.001} & 0.019 & 0.179 & 0.139 & 0.118 & \multirow[t]{3}{*}{0.021} \\
\hline & $\operatorname{Exp}_{2}$ & -0.008 & 0.014 & 0.003 & 0.002 & & -0.204 & 0.339 & 0.067 & 0.046 & \\
\hline & $\operatorname{Exp}_{3}$ & 0.003 & 0.027 & 0.009 & 0.008 & & 0.075 & 0.639 & 0.216 & 0.195 & \\
\hline \multirow{5}{*}{ हี } & $\operatorname{Exp}_{1}$ & 0.029 & 0.006 & 0.012 & -0.008 & \multirow[t]{5}{*}{0.020} & 0.686 & 0.148 & 0.283 & -0.191 & \multirow[t]{5}{*}{0.473} \\
\hline & $\operatorname{Exp}_{2}$ & 0.013 & 0.020 & 0.017 & -0.003 & & 0.324 & 0.485 & 0.404 & -0.069 & \\
\hline & $\operatorname{Exp}_{3}$ & 0.015 & 0.022 & 0.017 & -0.003 & & 0.362 & 0.531 & 0.404 & -0.069 & \\
\hline & $\operatorname{Exp}_{4}$ & 0.019 & 0.033 & 0.022 & 0.003 & & 0.450 & 0.785 & 0.534 & 0.061 & \\
\hline & $\operatorname{Exp}_{5}$ & 0.020 & 0.022 & 0.021 & 0.001 & & 0.478 & 0.536 & 0.493 & 0.019 & \\
\hline
\end{tabular}

From the monthly rainfall sums of the different model runs, it is evident that the inverse rainfall calculations differ significantly at the beginning of the simulation. In the first month the reference scenario results in a monthly rainfall sum of $30 \mathrm{~mm}$, the dry scenario in $111 \mathrm{~mm}$ and the wet scenario in only $9 \mathrm{~mm}$. Generally, the model will always strive towards an equilibrium in its system states, which are a function of the model structure and parameters. In the scenario "wet" a lot of water is stored in the states of the model at the beginning, with the result that little inverse rainfall is calculated. In the dry scenario, on the other hand, a higher amount of rainfall is estimated, since less water is stored in the states at the beginning. With time, however, the different system states converge. In consequence, also the inverse rainfall values converge and after 9 months no differences are visible.

Extreme assumptions were made concerning the dry and wet scenarios, since the intention of $\operatorname{Exp}_{6}$ is to evaluate the general influences of the cold states and spin-up time on the inferred rainfall. In particular, the long memory of the ground water storage explains the long warm-up period in the presented results. In practice, reasonable cold states must therefore be defined at start-up, as is the case for forward models formulated in a state-space approach. After an adequate spin-up time the system states will however converge, leading to deterministic and unique inverse rainfall estimates.

\section{Summary and outlook}

A calibrated rainfall-runoff model (forward model) reflects the catchment processes leading to runoff generation. Thus, inverting the model, i.e. calculating rainfall from runoff, yields the temporally disintegrated rainfall. In this paper we applied a conceptual rainfall-runoff model, which is inverted in an iterative approach, to simulate catchment rainfall from observed runoff. The precondition of invertibility of the model equations is successfully tested with virtual experiments, in which simulated runoff time series are used as input into the inverse model to derive rainfall. Additional virtual experiments are performed, in which noise is added to the runoff input time series to analyse the effects of possible short-term errors in runoff on the inferred precipitation rates.

The approach is applied and tested in two study areas in Austria. The estimated inverse rainfall is compared with two different rainfall realisations: in addition to ground observations, areal rainfall fields of the INCA system are used. Hourly data are available for the years 2006-2009. Only the months of June-September are used, as the inverse model can only be applied to simulate rainfall in periods in which runoff is not influenced by snowmelt (i.e. summer months).

In a first step, the forward model is calibrated against runoff observations. To evaluate the influences of (i) different model parameters due to different calibration periods and lengths, (ii) different runoff observations and (iii) different parameter optimisation data based on the runoff and rainfall calculations, several simulation experiments are performed. Additionally, the influence of different initial conditions on the rainfall simulations are evaluated.

The forward model mostly shows stable results in both catchments and reproduces the dynamics and variability of the catchment responses to rainfall in a satisfactory manner. Only the simulation experiment in which a single summer was used for parameter calibration shows a larger deterioration of the model performance in the validation period and independent years. The model parameters are then used for deriving catchment rainfall from runoff observations.

The cumulative rainfall curves of the different rainfall realisations (ground observation, $P_{\mathrm{obs}}$; INCA, $P_{\text {Inca }}$; and inverse rainfall from the different simulation experiments, $P_{\text {inv }}$ ) are very similar, suggesting that the inverse model is capable of representing the long-term quantitative rainfall conditions of the catchment. About $60 \%$ (Schliefau) and $45 \%$ (Krems) of rainfall is lost to the atmosphere due to actual evapotranspiration $\left(\mathrm{ET}_{\mathrm{a}}\right)$. If the model would not capture $\mathrm{ET}_{\mathrm{a}}$ adequately, the cumulative rainfall curves would not follow the observa- 
tions so closely. This is also the case for independent validation periods and years, which were not used in the calibration.

The correlation between $P_{\text {inv }}$ and $P_{\mathrm{obs}}$, although rather low, is higher or of the same magnitude compared to the correlation between $P_{\mathrm{obs}}$ and $P_{\text {Inca }}$, suggesting that the inverse model also reflects the timing of rainfall with the same quality as INCA. This is especially the case for the aggregated daily rainfall values. The correlation between $P_{\mathrm{inv}}$ and $P_{\mathrm{obs}}$ is mostly stable for the calibration, validation and, in the single years, independent of the simulation experiment. However, again, for the simulation experiment with only a single summer for parameter calibration, a larger spread in the correlation for the single years is visible. An increase in observed runoff $\left(\operatorname{Exp}_{4}\right)$ does not show negative effects on the inverse rainfall measured by the correlation coefficient. A larger bias between observed and modelled rainfall is however visible in $\operatorname{Exp}_{4}$. Generally, the simulation experiment with the highest performance in the runoff simulation also shows the highest correlation values in the rainfall simulations.

To test if the inverse rainfall is conditioned by observed rainfall used as calibration input, additional model calibration is conducted using independent INCA data as driving rainfall input for the forward model calibration. The simulation of inverse rainfall on the basis of this model parameter set shows similar results as before, suggesting that the inverse rainfall is not conditioned to the rainfall input used for model calibration. This result is interesting, since it shows that the inverse model provides reasonable results in the case where the forward model is calibrated with rainfall data that are independent from the observed rainfall in the proximity of the catchment. Generally, the results do not differ substantially between the two test catchments.

Since the inverse model is formulated in a state-space approach additional simulations are performed with differing cold states at the beginning of the simulations. Here the results show that the inferred rainfall values converge to identical values after an adequate spin-up time.

Like with most environmental models, a calibration of the forward model is necessary. It is clear that the application of the inverse model is therefore not possible if the catchment is completely ungauged. However, this issue is comparable to the application of conventional rainfall-runoff models in gauged and ungauged catchments. As long as a rainfallrunoff model shows reasonable results for the calibration and validation period, the model can be used for different practical applications, e.g. environmental change impact studies, design flood estimations or flood forecasting. This is also conceivable for the inverse model, since additional information on the catchment rainfall is made available for potential practical applications mentioned above. This additional information is not solely limited to the simulated hourly data but also includes the aggregated daily rainfall rates, which show a significant higher correlation to the observed values.
It can be concluded that the application of the inverse model is a feasible approach to gain additional information on the mean areal rainfall values. The mean areal rainfall values may be used to enhance interpolated rainfall fields, e.g. for the estimation of rainfall correction factors or the parameterisation of elevation dependency. With the inverse model, it is not possible to calculate solid rainfall. In rainless periods where it is clear that snowmelt is dominating runoff (e.g. in spring), the inverse model can however be used to quantify the snowmelt contribution.

Areal rainfall estimates leading to extreme flood events are afflicted with major uncertainties. This is underlined by the results where the largest deviations between observed and modelled rainfall are found during flood events. Here the inverse modelling approach can be used as an additional information source concerning the rainfall conditions during extreme events.

The inverse model was applied to two catchments. The application and analysis of the proposed method to a wider range of catchments with differing hydrological characteristics will therefore be an important task in the near future. Further investigations should include water-limited catchments with an aridity index far lower than 1 , where the influences of high evapotranspiration on the inferred rainfall must be investigated.

In the presented work several different model parameter sets were used as a basis to calculate inverse rainfall. In further works the influences and uncertainties in the inverse rainfall, which arise from different model parameters, should be analysed systematically. Additionally, a comparison of inverse rainfall estimates from a different model structure for the two catchments with our results would be of interest, in order to check the links between the performance of the forward model and the results obtained by the inversion method. 


\section{Appendix A}

The forward model is formulated as follows, considering parameters and variables in Tables 2 and 3:

$$
\begin{aligned}
& B_{\mathrm{WI}_{t}}=\max \left(\min \left(\mathrm{INTMAX}, B_{\mathrm{WI}_{t-1}}+0.5 R_{t}-E T_{\mathrm{I}_{t}}\right), 0\right) \\
& =\max \left(\operatorname { m i n } \left(\mathrm{INTMAX}, B_{\mathrm{WI}_{t-1}}+0.5 R_{t}\right.\right. \\
& \left.-f\left(\mathrm{ET}_{\mathrm{p}_{t}}, \mathrm{INTMAX}\right), 0\right) \text {, } \\
& R \_\operatorname{Soil}_{t}=0.5 R_{t}+\max \left(B_{\mathrm{WI}_{t-1}}+0.5 R_{t}\right. \\
& -\mathrm{ET}_{\mathrm{I}_{t}} \text { - INTMAX, 0), } \\
& B_{\mathrm{W}_{t}}=B_{\mathrm{W}_{t-1}}+R \_S_{-} i_{l}-\mathrm{ET}_{\mathrm{G}_{t}}-Q_{1_{t}}-Q_{2_{t}} \\
& =B_{\mathrm{W}_{t-1}}+R \_ \text {Soil }_{t}-\min \left(\frac{B_{\mathrm{W}_{t-1}}}{\text { FKFAK } \times M}, 1\right) \\
& \left(\mathrm{ET}_{\mathrm{p}_{t}}-\mathrm{ET}_{\mathrm{I}_{t}}\right) \text { ETVEGCOR }-R \_R_{-} \text {Soil }_{t} \\
& \left(\frac{B_{\mathrm{W} 0} t-1}{M}\right)^{\mathrm{BETA}}-f(\mathrm{PEX} 2) B_{\mathrm{W} 0_{t-1}} \text {, }
\end{aligned}
$$

$$
\begin{aligned}
B_{\mathrm{W} 3_{t}} & =B_{\mathrm{W}_{3-1}}+Q_{\mathrm{VS}_{t}}-Q_{\mathrm{AB}_{t}} \\
& =B_{\mathrm{W} 3_{t-1}}+\beta_{2} B_{\mathrm{W} 2_{t-1}}-\alpha_{3} B_{\mathrm{W} 3_{t-1}},
\end{aligned}
$$$$
B_{\mathrm{W}_{4}}=B_{\mathrm{W}_{t-1}}+Q_{1_{t}}+Q_{\mathrm{AB}_{t}}+Q_{\mathrm{AB}_{t}}-Q_{\mathrm{sim}_{t}}
$$$$
=B_{\mathrm{W} 4_{t-1}}+R_{-} \operatorname{Soil}_{t}\left(\frac{B_{\mathrm{W}_{t-1}}}{M}\right)^{\mathrm{BETA}}
$$$$
+\alpha_{2} \max \left(B_{\mathrm{W} 2_{t-1}}-H 2,0\right)+\alpha_{3} B_{\mathrm{W} 3_{t-1}}-\alpha_{4} B_{\mathrm{W} 4_{t-1}} \text {, }
$$

with

$\alpha_{i}=\frac{\Delta t}{\mathrm{TAB}_{i}}$ and

$\beta_{i}=\frac{\Delta t}{\mathrm{TVS}_{i}}$,

where $\mathrm{TAB}_{i} / \mathrm{TVS}_{i}$ are recession coefficients and $\Delta t$ is the modelling time step in units of hours. $\alpha$ and $\beta$ vary with modelling time step and represent smoothing functions of the linear reservoirs.

Equations (A1)-(A8) are simplified representations of the model algorithm. min/max operators, by introducing discontinuities, can lead to noninvertibility. Equations (A4) and (A6) do not include a threshold function in the actual model code. The differential equations of the linear reservoirs are solved analytically. An internal time step discretization is included in the code, to guarantee that the transition between system states above and below the threshold value is solved exactly. Equation (A3), representing the soil layer, does include a $\min ()$ operator for estimating the ratio between actual and potential evapotranspiration as a function of soil water content. This is however not a limiting factor for the inversion, since this factor is a function of the preceding soil state $\mathrm{BW0}_{t-1}$, which is known. Only $50 \%$ of rainfall is used as input into the interception storage $\mathrm{B}_{\mathrm{WI}}$. By assuming that the other $50 \%$ is always throughfall, Eqs. (A1) and (A2) also do not limit the inversion, since a continuous signal through the whole model cascade is guaranteed. The recession coefficient representing percolation processes in the soil layer exhibits a nonlinear characteristic and is calculated as a function of actual soil water content and a as a function of the form parameter PEX2 (-). This model concept reflects the fact that higher soil moisture levels lead to higher soil permeability values. These induce higher percolation rates which are reflected by lower recession coefficients. 
Acknowledgements. The authors thank the three anonymous reviewers and the editor, Roger Moussa, for their valuable thoughts, comments and suggestions, which helped to improve the manuscript.

Data was provided by the Federal Ministry of Agriculture, Forestry, Environment and Water Management and the Central Institute for Meteorology and Geodynamics (ZAMG).

Edited by: R. Moussa

\section{References}

Ahrens, B., Jasper, K., and Gurtz, J.: On ALADIN precipitation modeling and validation in an Alpine watershed, Ann. Geophys., 21, 627-637, doi:10.5194/angeo-21-627-2003, 2003.

Allen, R. G., Pereira, L. S., Raes, D., and Smith, M.: Crop evapotranspiration: guidelines for computing crop water requirements, FAO Irrigation and Drainage Paper No. 56, Rome, Italy, 1998.

Bergström, S.: The HBV model, in: Computer Models of Watershed Hydrology, edited by: Singh, V. P., Water Resources Publications, Highland Ranch, CO, USA, 443-476, 1995.

Bica, B., Herrnegger, M., Kann, A., and Nachtnebel, H. P.: HYDROCAST - Enhanced estimation of areal rainfallby combining a meteorological nowcasting system with a hydrological model, Final report, Austrian Academy of Science, Vienna, doi:10.1553/hydrocast2011, 2011.

BMLFUW: Hydrological Atlas of Austria, 3rd Edn., Bundesministerium für Land- und Forstwirtschaft, Umwelt und Wasserwirtschaft, Vienna, Austria, ISBN: 3-85437-250-7, 2007.

BMLFUW: Hydrographical Yearbook of Austria, Abteilung VII 3 - Wasserhaushalt im Bundesministerium für Land und Forstwirtschaft, Umwelt und Wasserwirtschaft, Vienna, Austria, 2009.

Brent, R. P.: Algorithms for Minimization without Derivatives, Prentice-Hall, Englewood Cliffs, NJ, USA, 1973.

de Jong, C., List, F., and Ergenzinger, C.: Experimental hydrological analyses in the Dischma based on daily and seasonal evaporation, Nord. Hydrol., 33, 1-14, 2002.

di Baldassarre, G. and Montanari, A.: Uncertainty in river discharge observations: a quantitative analysis, Hydrol. Earth Syst. Sci., 13, 913-921, doi:10.5194/hess-13-913-2009, 2009.

Duan, Q., Sorooshian, S., and Gupta, V. K.: Effective and efficient global optimization for conceptual rainfall-runoff models, Water Resour. Res., 28, 1015-1031, 1992.

Eder, G., Fuchs, M., Nachtnebel, H. P., and Loibl, W.: Semidistributed modelling of the monthly water balance in an alpine catchment, Hydrol. Process., 19, 2339-2360, 2005.

Elias, V., Tesar, M., and Buchtele, J.: Occult precipitation: sampling, chemical analysis and process modeling in the Sumava Mts. (Czech Republic) and in the Taunus Mts. (Germany), J. Hydrol., 166, 409-420, 1995.

Fekete, B. M., Vorosmarty, C. J., Roads, J. O., and Willmot, C. J.: Uncertainties in precipitation and their impacts on runoff estimates, J. Climate, 17, 294-304, 2004.

Goodison, B. E., Louie, P. Y. T., and Yang, D.: WMO solid precipitation measurement intercomparison, Instruments and Observing Methods Rep. 67 (WMO/TD 872), World Meteorological Organization, Geneva, Switzerland, 318 pp., 1998.
Groetsch, C.: Inverse Problems in Mathematical Sciences, Vieweg Mathematics for Scientists and Engineers, Wiesbaden, 1993.

Haiden, T. and Pistotnik, G.: Intensity-dependent parameterization of elevation effects in precipitation analysis, Adv. Geosci., 20, 33-38, doi:10.5194/adgeo-20-33-2009, 2009.

Haiden, T., Kann, A., Wittman, C., Pistotnik, G., Bica, B., and Gruber, C.: The Integrated Nowcasting through Comprehensive Analysis (INCA) system and its validation over the Eastern Alpine region, Weather Forecast., 26, 166-183, doi:10.1175/2010WAF2222451.1, 2011.

Hargreaves, G. H. and Samani, Z. A.: Estimating potential evapotranspiration, J. Irr. Drain. Div.-ASCE, 108, 225-230, 1982.

Herrnegger, M.: Zeitlich hochaufgelöste inverse Modellierung von Gebietsniederschlägen aus Abflussmessungen, $\mathrm{PhD}$ thesis, Institute of Water Management, Hydrology and Hydraulic Engineering, University of Natural Resources and Life Sciences, Vienna, Austria, 2013.

Herrnegger, M., Nachtnebel, H. P., and Haiden, T.: Evapotranspiration in high alpine catchments - an important part of the water balance!, Hydrol. Res., 43, 460-475, 2012.

Hino, M. and Hasabe, M.: Analysis of hydrologic characteristics from runoff data - a hydrologic inverse problem, J. Hydrol., 49, 287-313, 1981.

Jacobs, A. F. G., Heusinkveld, B. G., and Wichink Kruit, R. J.: Contribution of dew to the water budget of a grassland area in the Netherlands, Water Resour. Res., 42, W03415, doi:10.1029/2005WR004055, 2006.

Jasper, K. and Kaufmann, P.: Coupled runoff simulations as validation tools for atmospheric models at the regional scale, Q. J. Roy. Meteorol. Soc., 129, 673-692, 2007.

Jasper, K., Gurtz, J., and Lang, H.: Advanced flood forecasting in Alpine watersheds by coupling meteorological observations and forecasts with a distributed hydrological model, J. Hydrol., 267, 40-52, 2002.

Kirchner, J. W.: Catchments as simple dynamical systems: catchment characterization, rainfall-runoff modeling, and doing hydrology backward, Water Resour. Res., 45, W02429, doi:10.1029/2008WR006912, 2009.

Klemm, O. and Wrzesinski, T.: Fog deposition fluxes of water and ions to a mountainous site in Central Europe, Tellus, 59, 705714, 2007.

Kling, H.: Spatio-temporal modelling of the water balance of Austria, Dissertation, University of Natural Resources and Applied Life Sciences, 234 pp., available at: http://iwhw.boku.ac.at/ dissertationen/kling.pdf (last access: 7 October 2014), 2006.

Kling, H. and Nachtnebel, H. P.: A method for the regional estimation of runoff separation parameters for hydrological modelling, J. Hydrol., 364, 163-174, 2009.

Kling, H., Stanzel, P., Fuchs, M., and Nachtnebel, H. P.: Performance of the COSERO precipitation-runoff model under nonstationary conditions in basins with different climates, Hydrolog. Sci. J., 60, 1374-1393, doi:10.1080/02626667.2014.959956, 2015.

Krajewski, W. F. and Smith, J. A.: Radar hydrology: rainfall estimation, Adv. Water Resour., 25, 1387-13, 2002.

Krajewski, W. F., Villarini, G., and Smith, J. A.: RADARrainfall uncertainties, B. Am. Meteorol. Soc., 91, 87-94, doi:10.1175/2009BAMS2747.1, 2010. 
Krier, R., Matgen, P., Goergen, K., Pfister, L., Hoffmann, L., Kirchner, J. W., Uhlenbrook, S., and Savenije, H. H. G.: Inferring catchment precipitation by doing hydrology backward: a test in 24 small and mesoscale catchments in Luxembourg, Water Resour. Res., 48, W10525, doi:10.1029/2011WR010657, 2012.

Kuczera, G., Kavetski, D., Franks, S., and Thyer, M.: Towards a Bayesian total error analysis of conceptual rainfall-runoff models: characterising model error using storm-dependent parameters, J. Hydrol., 331, 161-177, 2006.

Kunstmann, H. and Stadler, C.: High resolution distributed atmospheric-hydrological modeling for Alpine catchments, J. Hydrol., 314, 105-124, 2005.

Liu, Y., Weerts, A. H., Clark, M., Hendricks Franssen, H.-J., Kumar, S., Moradkhani, H., Seo, D.-J., Schwanenberg, D., Smith, P., van Dijk, A. I. J. M., van Velzen, N., He, M., Lee, H., Noh, S. J., Rakovec, O., and Restrepo, P.: Advancing data assimilation in operational hydrologic forecasting: progresses, challenges, and emerging opportunities, Hydrol. Earth Syst. Sci., 16, 3863-3887, doi:10.5194/hess-16-3863-2012, 2012.

McLaughlin, D.: An integrated approach to hydrologic data assimilation: interpolation, smoothing and filtering, Adv. Water Resour., 25, 1275-1286, 2002.

McMillan, H., Freer, J., Pappenberger, F., Krueger, T., and Clark, M.: Impacts of uncertain river flow data on rainfall-runoff model calibration and discharge predictions, Hydrol. Process., 24, 1270-1284, doi:10.1002/Hyp.7587, 2010.

Nachtnebel, H. P., Baumung, S., and Lettl, W.: Abflussprognosemodell für das Einzugsgebiet der Enns und Steyr, report, Institute of Water Management, Hydology and Hydraulic Engineering, University of Natural Resources and Applied Life Sciences, Vienna, Austria, 1993.

Nachtnebel, H. P., Haberl, U., Stanzel, Ph., Kahl, B., Holzmann, H., and Pfaffenwimmer, Th.: Hydrologische Abflussmodellierung Teil 3, in: Amt der Salzburger Landesregierung: HydrisII Hydrologisches Informationssystem zur Hochwasservorhersage im Land Salzburg, Amt der Salzburger Landesregierung, Salzburg, Austria, 341 pp., 2009a.

Nachtnebel, H. P., Senoner, T., Stanzel, P., Kahl, B., Hernegger, M., Haberl, U. and Pfaffenwimmer, T.: Inflow prediction system for the Hydropower Plant Gabčíkovo, Part 3 - Hydrologic Modelling, Slovenské elektrárne, a.s. Bratislava, Slovakia, 139 pp., 2009b.

Nachtnebel, H. P., Herrnegger, M., Kahl, B., and Hepp, G.: Meteorologisch-hydrologisches Warnsystem Steyr: Endbericht und Technische Dokumentation - Teil 3: Hydrologische Abflussmodellierung, Amt der OÖ Landesregierung, Abteilung Wasserwirtschaft, Schutzwasserwirtschaft und Hydrographie, Innsbruck, Austria, 197 pp., 2010a.

Nachtnebel, H. P., Senoner, T., Kahl, B., Apperl, B., and Waldhör, B.: Hochwasserprognosesystem Ybbs - Hydrologische Abflussmodellierung, Amt der NÖ Landesregierung, St. Pölten, Austria, 176 pp., 2010b.

Nash, J. E. and Sutcliffe, J. V.: River flow forecasting through conceptual models, Part I: A discussion of principles, J. Hydrol., 10, 282-290, 1970.

Pappenberger, F., Matgen, P., Beven, K. J., Henry, J. B., Pfister, L., and de Fraipont, P.: Influence of uncertain boundary conditions and model structure on flood inundation predictions, Adv. Water Resour., 29, 1430-1449, 2006.
Pelletier, M. P.: Uncertainties in the determination of river discharge: a literature review, Can. J. Civil Eng., 15, 834-850, 1987.

Perrin, C., Michel, C., and Andréassian, V.: Does a large number of parameters enhance model performance? Comparative assessment of common catchment model structures on 429 catchments, J. Hydrol., 242, 275-301, 2001.

Press, W. H., Teukolsky, S. A., Vetterling, W. T., and Flannery, B. P.: Numerical Recipes in FORTRAN, The Art of Scientific Computing, Cambridge Univ. Press, New York, 965 pp., 1992.

Seibert, J.: Reliability of model predictions outside calibration conditions, Nord. Hydrol., 34, 477-492, 2003.

Seibert, J. and Morén, A.-S.: Reducing systematic errors in rainfall measurements using a new type of gauge, Agr. Forest Meteorol., 98-99, 341-348, 1999.

Sevruk, B.: Methodische Untersuchungen des systematischen Messfehlers der Hellmann-Regenmesser im Sommerhalbjahr in der Schweiz, dissertation, Eidgenöss. Techn. Hochsch. Zürich, Zürich, Switzerland, 1981.

Sevruk, B.: Correction of precipitation measurements. Proc. Workshop on the Correction of Precipitation Measurements, in: Zürcher Geographische Schriften, ETH Zurich, Zurich, Switzerland, p. 289, 1986.

Sevruk, B. and Nespor, V.: Empirical and theoretical assessment of the wind induced error of rain measurement, Water Sci. Technol., 37, 171-178, 1998.

Simoni, S., Padoan, S., Nadeau, D. F., Diebold, M., Porporato, A., Barrenetxea, G., Ingelrest, F., Vetterli, M., and Parlange, M. B.: Hydrologic response of an alpine watershed: application of a meteorological wireless sensor network to understand streamflow generation, Water Resour. Res., 47, W10524, doi:10.1029/2011WR010730, 2011.

Stanzel, P., Kahl, B., Haberl, U., Herrnegger, M., and Nachtnebel, H. P.: Continuous hydrological modeling in the context of real time flood forecasting in alpine Danube tributary catchments, IOP Conf. Ser., 4, 012005, doi:10.1088/17551307/4/1/012005, 2008.

Sugawara, M.: On the weights of precipitation stations, in: Advances in Theoretical Hydrology, edited by: O'Kane, J. P., Elsevier Science Publishers, Amsterdam, 59-74, 1992.

Tarantola, A.: Inverse Problem Theory and Methods for Model Parameter Estimation, Society for Industrial and Applied Mathematics, Philadelphia, 352 pp., 2005.

Valéry, A., Andréassian, V., and Perrin, C.: Inverting the hydrological cycle: when streamflow measurements help assess altitudinal precipitation gradients in mountain areas, in: New Approaches to Hydrological Prediction in Data-sparse Regions, IAHS Publ., 333, 281-286, 2009.

Valéry, A., Andréassian, V., and Perrin, C.: Regionalisation of rainfall and air temperature over high-altitude catchments - learning from outliers, Hydrolog. Sci. J., 55, 928-940, 2010.

van Genuchten, M. T.: A closed-form equation for predicting the hydraulic conductivity of unsaturated soils, Soil Sci. Soc. Am. J., 44, 892-898, 1980.

Vrugt, J. A., ter Braak, C. J. F., Clark, M. P., Hyman, J. M., and Robinson, B. A.: Treatment of input uncertainty in hydrologic modeling: doing hydrology backward with Markov chain Monte Carlo simulation, Water Resour. Res., 44, W00B09, doi:10.1029/2007WR006720, 2008. 
Wood, S. J., Jones, D. A., and Moore, R. J.: Accuracy of rainfall measurement for scales of hydrological interest, Hydrol. Earth Syst. Sci., 4, 531-543, doi:10.5194/hess-4-531-2000, 2000. 